\title{
Dam Safety: Use of Seismic Monitoring Instrumentation in Dams
}

\author{
Nasrat Adamo ${ }^{1}$, Nadhir Al-Ansari², Varoujan Sissakian ${ }^{3}$, Jan Laue ${ }^{4}$ \\ and Sven Knutsson ${ }^{5}$
}

\begin{abstract}
Seismic instrumentation of dams and reservoirs sites is accepted today as a valuable tool to understand significant seismic hazards facing existing dams or future planed dams. With the advent of digital seismic accelerometers and recorders, it can now be used today as an integral part of dam safety monitoring systems. Outputs of these instruments help in understanding the dynamic response of dams during earthquake, assessing the damage caused by such events and determining required upgrading works necessary for existing dams and designing of safer dams in the future. Measuring and recording by strong motion seismographs covers the induced Peak Ground Acceleration (PGA), velocity and displacement recorded on time scale to indicate the intensity and frequency of ground vibration at the site during seismic events. Seismometers for such measurements and recordings have undergone considerable evolution and there exist today a variety of these instruments with high degree of refinement which can even provide for remote sensing. In this work, this development is outlined and examples of seismic instrumentation in strategic dams are described. Damages to actual concrete and embankment dams of various types are described indicating the associated PGAs experienced during the mentioned earthquakes. Damages in the form of cracking, increased seepage, additional settlements and displacements are described to show type and extent of possible consequences of such events on dams. The reached conclusion is that seismic instrumentation systems are desirable and highly recommendable for all types of dams; existing and future ones and their high cost is justified by the service they provide.
\end{abstract}

\footnotetext{
${ }^{1}$ Consultant Dam Engineer, Sweden.

2 Lulea University of Technology, Lulea 971 87, Sweden.

${ }^{3}$ Lecturer, University of Kurdistan Hewler and Private Consultant Geologist, Erbil.

${ }^{4}$ Lulea University of Technology, Lulea 971 87, Sweden.

5 Lulea University of Technology, Lulea 971 87, Sweden.
} 
Keywords: Seismic instrumentation, seismic hazard, accelerometers, safety monitoring systems, dynamic response, strong motion seismograph, ground vibration, seismometers, remote sensing.

\section{General}

History of recorded dam failures and incidents due to earthquake ground shaking indicates that many dams had failed or badly damaged by such events during the second half of the nineteenth century and first half of the twentieth century [1]. Design criteria and methods of dynamic analysis of large concrete and embankment dams have undergone substantial changes since the 1930s after Westergaard had developed his theory of structures based on the elastic theory, and loading due to earthquake action was introduced into their design. Until the 1960's, seismic analysis of dams consisted essentially of the use of the seismic coefficient method, in which a static horizontal inertia force was applied to the potential sliding mass in embankment dams, or center of gravity of concrete dams, in an otherwise conventional static limit analysis. The magnitude of the inertia force was chosen on the basis of judgment and tradition and it was represented by a seismic coefficient multiplied by fraction of the dam weight. Typically, a seismic coefficient value of $0.1 \mathrm{~g}$ was used for most dams. In exceptional cases in Japan and Iran, slightly higher values were considered. The seismic coefficients had no clear physical relation with the design ground motions and the seismic hazard at the dam site. Moreover, the dynamic response was determined by a pseudostatic analysis, which does not account for the dynamic characteristics of the dam.

Due to the simplicity of this method it remained in use, although it had no scientific basis, until late 1980s, but gradually has been replaced, especially for moderate or significate risk dams, by more rational use of analysis of the actual response of dams. This has raised the need for advanced monitoring instrumentation capable of recording peak ground acceleration and its variation with time during the event, Early seismic instruments for dams were developed during the 1930s by the United State Bureau of Reclamation (USBR). Most technological advances in this field, however, have occurred during the 1970s and after; when number of vibration measuring devices have been developed and of these, the seismograph (accelerograph) is now the most commonly used seismic instrument. This instrument consists of a sensor (seismometer or accelerometer) and a mechanism for producing a permanent record of the vibration applied to the sensor. Nearly all seismic instruments in use today utilize servo-accelerometers that have the ability to measure motion in a single horizontal, vertical, or transverse plane. Most of the devices are considered "strong motion" instruments that record significant movement, as opposed to micro-seismic activity that requires the use of signal conditioner or enhancers to magnify the motion to recordable level. The first strong motion instrument installed by USBR was Hoover Dam in 1936 [2].

Obtaining data on ground motion during earthquakes to which all types of structures such as high-rise building, power stations, bridges and dams is very important for 
the investigation of the dynamic behavior of these structures and for defining design criteria of future similar structures. This has given rise to the development of networks of strong motion instruments installed in various countries of the world and especially in seismic regions to gather such information.

In the beginning of the 70s, networks of strong earthquakes recording instruments were installed in several seismic regions in the world such as USA, Japan, Italy, former Yugoslavia and others. This example was later followed by several other countries like Mexico, New Zealand, Iran, Turkey, Greece and others, thus at present, there is a relatively high number of such networks. Today, earth is being constantly monitored by over 20,000 strong motion seismometers deployed throughout the world, most of which transmit data in real time. As early as the late 19th century, Rebeur Paschwitz had understood the fundamental advantage of being able to study an earthquake from several points on the globe, and recent technological innovations have made it possible to record, digitize and relay seismic data to remote observatories.

Even with the large number of strong motion seismometer aforementioned, they are still not sufficient to cover all the seismically active regions in the world and to provide sufficient quantity of usable data. Therefore, large number of countries in the engineering practice apply records obtained by other countries. But, having in mind that earthquakes are characterized by:

1. the frequency and amplitude content, which depend on the geological and tectonic structure of the seism region.

2. the magnitude, and/or the intensity of the earthquake.

3. the origin depth.

4. the epicentral distance.

Then it is obvious that they differ from those recorded in other areas, even in cases when earthquakes of the same intensity are considered. Therefore, it is necessary to use records from the actual seismogene region, or if used from another region, then one should be careful, and, if possible, use records from a region having similar seismo-tectonic characteristics [3].

This development, however, has not precluded the need for installing strong motion instruments at medium and significant risk dams' sites to define the strong motion parameters at such sites which are defined and modified by geology and topographic conditions at their sites [4].

The outdated concept that seismic instrumentation of dams and reservoirs' sites is only a research tool has given way to the modern concept that seismic instrumentation is necessary to understand significant hazard dams' behavior in seismic areas. It is also desirable in traditionally non-seismic areas. With the advent with digital seismic equipment, it can now be an integral part of dam safety monitoring works. The digital earthquake data can be gathered by site personnel and remote control centers by use of computer programs. When the digital instrument is installed with modem and communication means, then remote access from several offices is available. 
These devices typically consist of three mutually-perpendicular accelerometers, a recording system, and triggering mechanism. To prevent accumulation of unwanted data, the instruments are usually set to be triggered at accelerations generated by nearby small earthquakes or more distant, larger earthquakes. They are expensive, especially considering that multiple instruments are necessary to record dynamic response at several locations on a structure, a foundation, or abutments. The devices must be properly maintained, so that they operate if an earthquake takes place.

Seismic instrumentation's installation should be considered on a case-by-case basis depending on; dam design, foundation materials, and methods of construction. Sitespecific seismotectonic data needs should be weighed against potential benefits before any seismic strong motion instrumentation is adopted [5].

\section{Seismographs and their Use in Dams}

The general term, seismograph, refers to all types of seismic instruments that record a permanent, continuous record of earth motion. The basic components of a seismograph include a frame anchored to the ground, one or more transducers, and a recorder. As the frame moves with the ground, the transducers respond according to the principles of dynamic equilibrium. Signals of horizontal motion in two planes and vertical motion may be sensed either electrically, optically, or mechanically. The motion sensed may be proportional to acceleration, velocity, or ground displacement. A triggering mechanism is provided to prevent accumulation of unwanted data and the instruments are usually set to be triggered at accelerations generated by nearby small earthquakes or more distant, larger earthquakes. These equipment are expensive, especially considering that multiple instruments are necessary to record dynamic response at several locations on a structure, a foundation, or abutments. The devices must be properly maintained, so that they operate if an earthquake takes place.

An example of seismograph is shown in Figure 1, which is of Kinemetrics seismograph, formerly used by the USBR $[6,7]$.

The earliest form of seismometers was known as early as 132 A. D. in China using pendulum as the principle seismic measuring device. The history of seismometers development from that time up to 1900 is given in the book "Early History of Seismometry to 1900 "'[8]. 


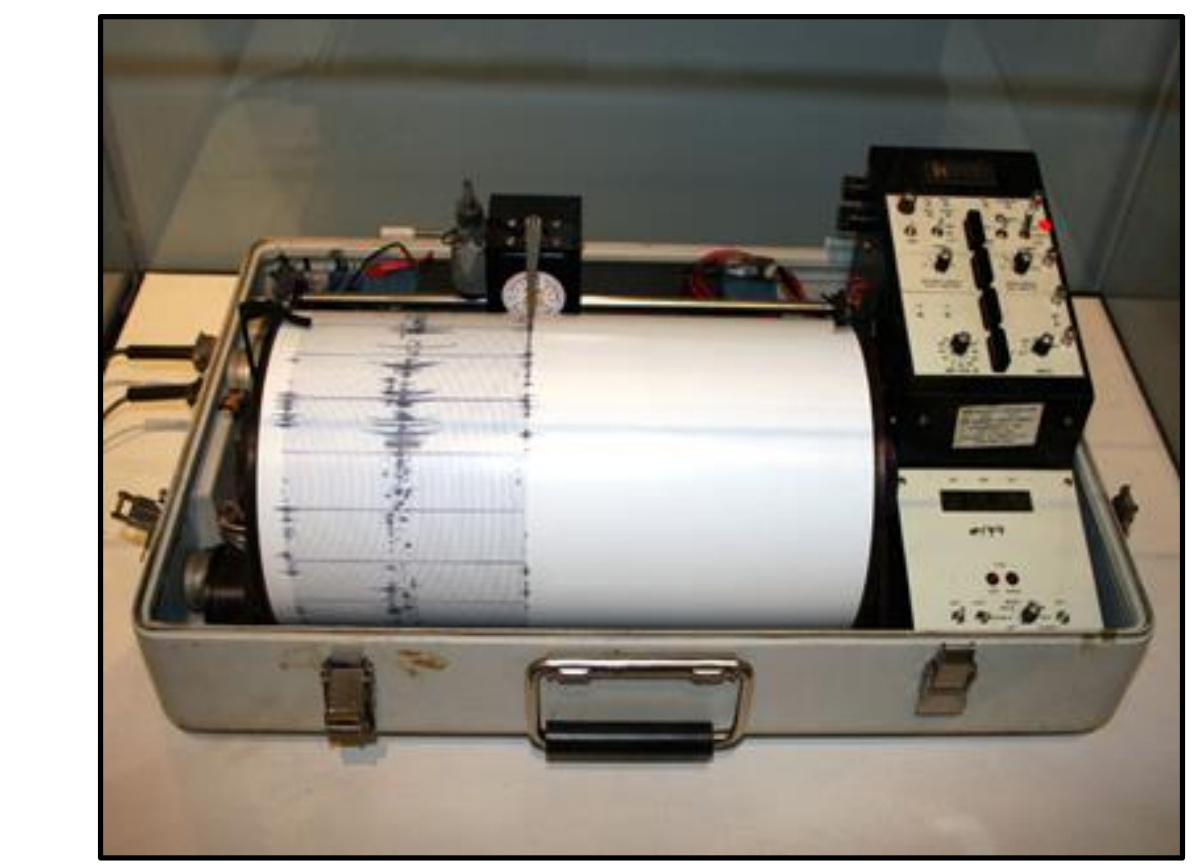

Figure 1: Kinemetrics seismograph, formerly used by the United States Department of the Interior [6] and [7].

Two main types of seismographs exist today as far as the recording of obtained data are concerned namely; analog recording seismographs and the digital recording seismographs.

In dams, a digital seismograph can be part of other data acquisition systems installed in such dam such as a trigger device for piezometer recordings or for slope stability during an earthquake, a telephone calling system to report an earthquake event, or a multi-recorder installation to study the response of particular appurtenant dam structure.

According to USBR practice, strong motion seismographs are categorized according to their placement location.

\section{i) Free field instruments}

It is recommended that such instruments are located near both abutments at the toe but at such distance beyond any significant influences of the dam on the recorded ground motion.

\section{ii) Input motion instruments}

They are to be placed at the downstream toe and to the abutments as close to the dam as possible. Most of these instruments are placed in prefabricated housing on concrete pads firmly secured to the underlying rock or surface material, but normally finding suitable locations at the toe is difficult due to various tail water conditions, and difficulties in locating them on the abutments can be due to restricted access due to topographic conditions. In abutment areas, an ideal installation in a spatially restricted area would be a small chamber in the natural material where maintenance problems could be minimized. Siting interior or 
subsurface input motion instruments consist of boreholes instrumentation in the foundation within selected galleries in concrete dams. Drainage and grouting galleries, when excavation in earth dam foundation, can be utilized as input motion sites for strong motion instruments.

\section{iii) Response instruments}

These are located on the dam to determine dam response to the vibration. Ideally, one or two response instruments are installed on the crest of both earth and concrete dams. The primary location is where maximum deformation during strong motion is expected, usually at the maximum section. A secondary section may be about one-third of the crest length from an abutment, such a location is basically for backup purposes. If a dynamic analysis of the structure has been done prior to strong motion instrument deployment, the response instrument location may be specified based on the analysis. Specified areas would be where lower safety factors and higher loads are expected. These locations are site specific for each structure. The locations for earth dams depend upon zoning geometry of the dam, types of materials used in the zones, and nature of the foundation; while for concrete dams depend upon type of the dam (gravity or arch), geometric configuration of the dam and nature of foundation materials [9].

One possible arrangement of instruments location is shown in Figure 2. This is given only as an example, but actual numbers and arrangements may be done after careful assessment of the needs based on type and importance of the dam and the seismic region where it is located, $[10,11]$.

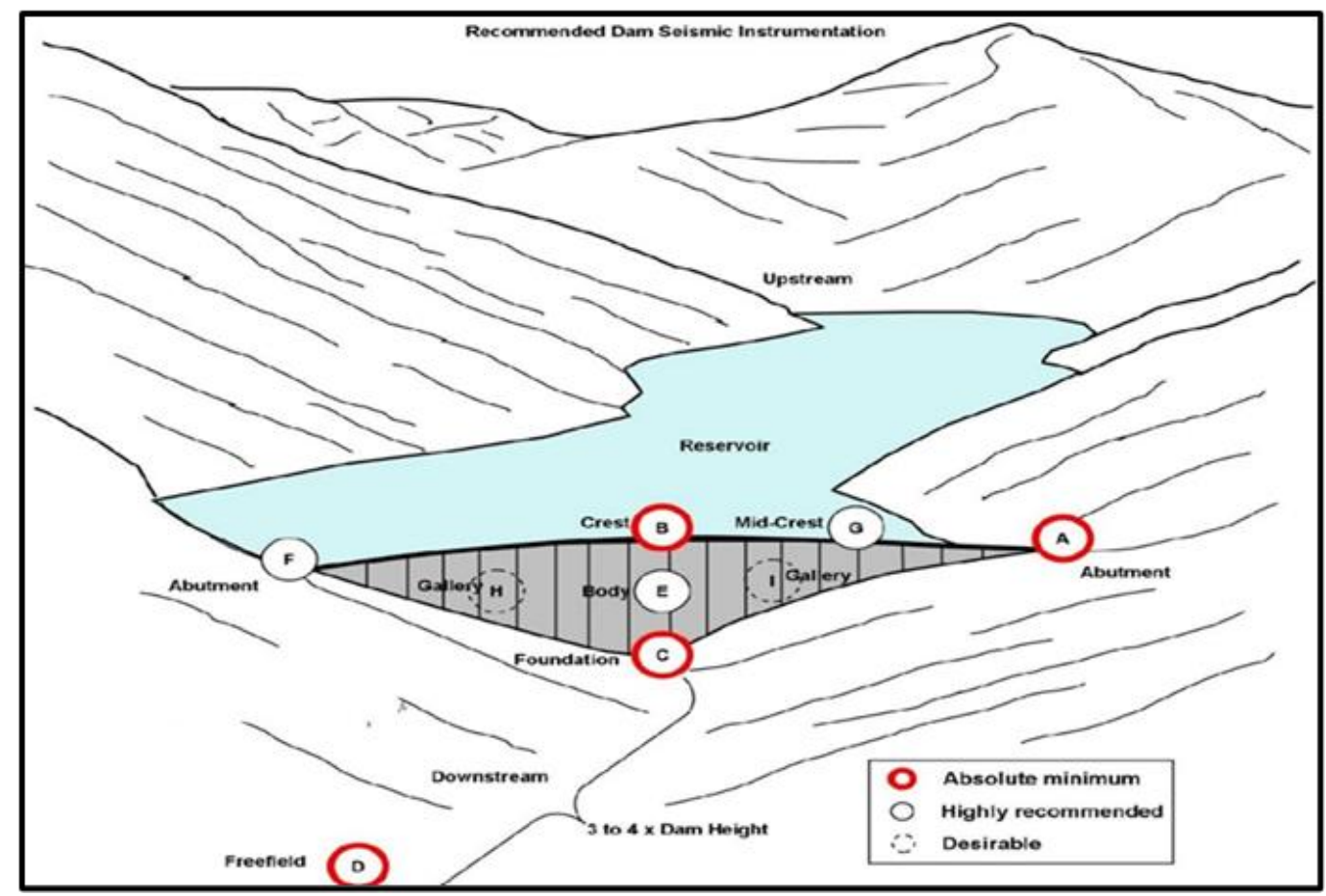

Figure 2: Example of dam seismic instrumentation [10, 11]. 
Basically, vibration measuring devices consist of sensors, signal conditioner, and a recorder or storage medium.

\section{i) Sensor}

The sensing devices used are electromechanical units that respond to motion and produce an electrical signal that is, within limits, proportional to displacement, velocity, or acceleration. Most sensors are models of single degree of freedom, spring-mass dashpot system. The measurement is usually made of the spring extension or compression with the resonant frequency and the damping of the system so proportioned as to produce an electrical signal that is an analog of either acceleration, velocity or displacement. Sensors may be located at the recording unit or placed in a remote location; such as in a drill hole, or elsewhere. Signals are transmitted by a coaxial cable to the signal conditioner. It is common for sensors to contain a starter or triggering device that activates the sensor at some predetermined acceleration, such 0.01 gravity. The sensor would then continue to operate as long as the motion is greater than that value, and for short time thereafter. These sensors act as seismic alarm devices (SAD) and they are installed where a display of peak acceleration is required immediately following an earthquake. The instruments measure acceleration, triaxially, vertical, longitudinal and transverse directions, and they are available in digital and analog models.

\section{ii) Signal Conditioner}

The term "signal conditioner" refers to all units and devices placed between the sensor and the final output data recorder. These devices are usually power amplifiers that are required to change the micropower signal level from the sensor to the macrolevel required to activate the recorder system. Signal conditioners also usually include sensitivity controls to permit a desired level of recorded signal.

Signal conditioning equipment may also include analog integration units for conversion of one measured parameter to another. The equipment may physically be part of the sensor unit, part of the recording unit, or may be separately packaged.

\section{iii) Recorder}

The recording unit is the final device in the system and is located in a protected environment in a secured area. The recorder presents the output in some usable form for evaluation and/or further use. Most recorders now being used produce historical records of the input phenomenon versus time as a paper record. Such records provide a quick method for visual inspection, and permit a rapid evaluation of peak amplitudes and other values. Detailed study of data in this form requires point- by point transcription of values for future computation. Automatic data handling can be obtained for the use of magnetic tape recorder and later playback on to computing systems. The most desirable system includes an output of both direct reading paper records for rapid field inspection; plus a magnetic tape for direct storage, which allows for later computer processing. Most recorders also provide a timing base that is recorded along with the sensor signals as a reference for determining the frequency of the vibration.

Generally, recorders may be provided as analog recording units or digital recording 
units. The analog type record data on $70 \mathrm{~mm}$ film which must be recovered under low light conditions and chemically processed to develop the film. A component diagram of such recorder is shown in Figure 3 [12].

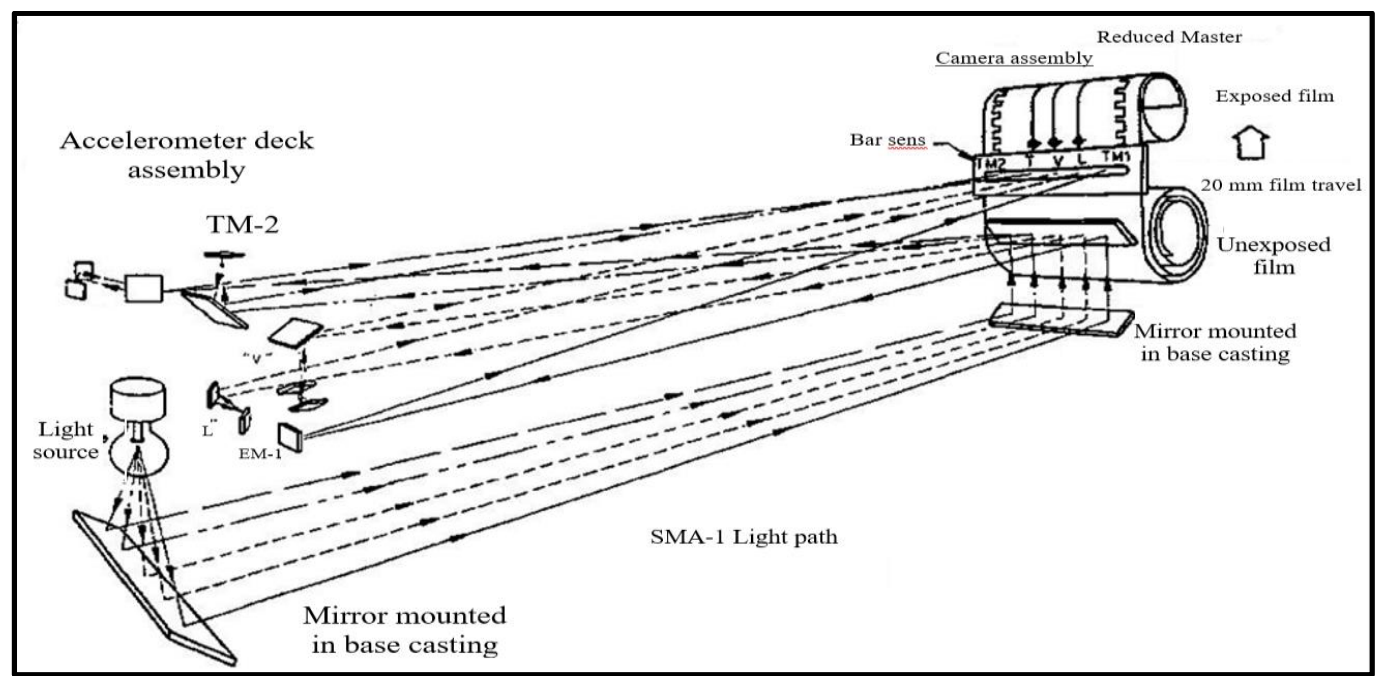

Figure 3: Analog/accelerograph component diagram showing working principles [12].

Digital recorder continuously digitalizes the three internal force balance accelerometers and stores data in solid state memory. The general arrangement of a digital accelerograph box is presented in Figure 4a, and a typical plot of such accelerograph is shown in in Figure 4b [12].
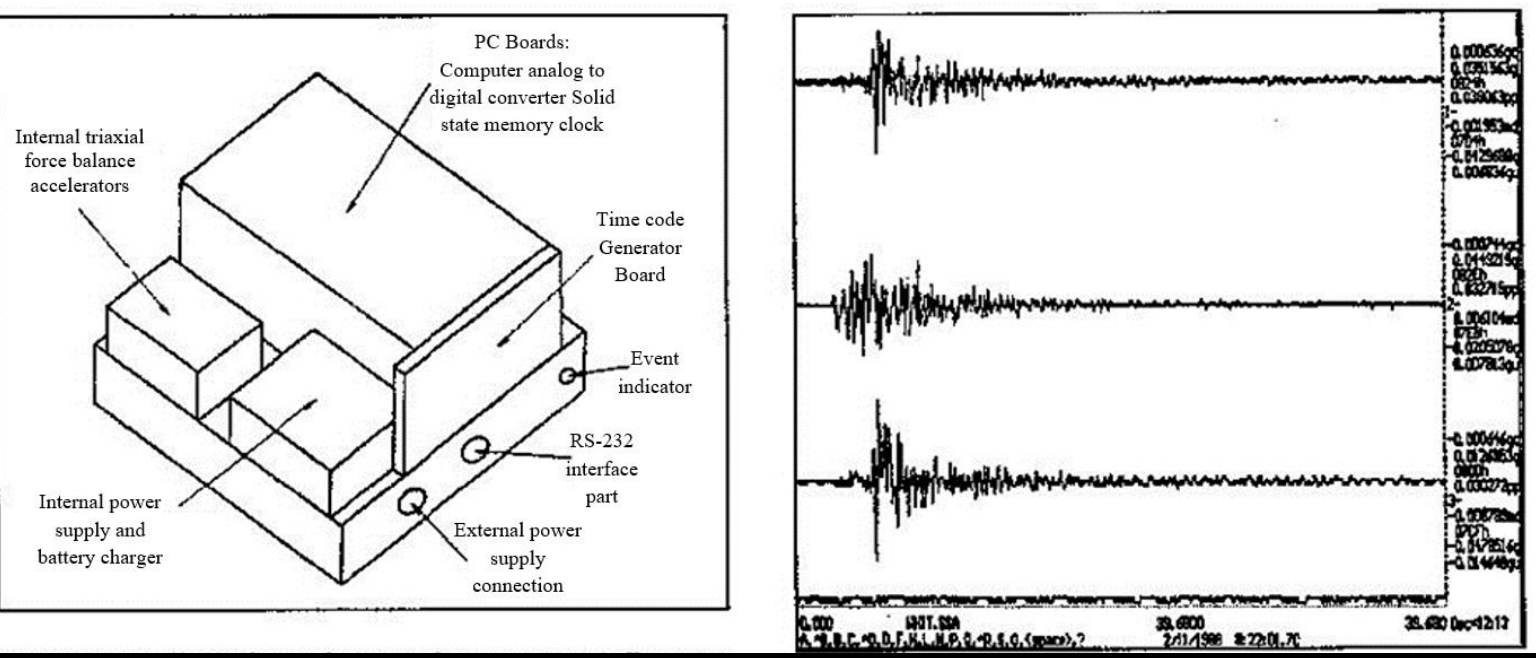

Figure 4: (a) On the left shows the general arrangement of a digital accelerograph. (b) On the right is a typical plot of such accelerograph [12]. 
Development of strong motion instrumentation from the early Chinese instrument up to now has gone very far and it is possible now that at each measuring point on a dam or other important structure a high dynamic mechanical force balance accelerometer is deployed. These devices collect raw acceleration data and transfer it to Data Acquisition System (DAS). From the DAS, the data is collected and sampled. It can then be transmitted to an offsite location or stored locally for automatic intelligent processing. The reliable level of remote monitoring eliminates the need for site visits for structures in remote locations. The system allows for tools to remove mundane data, noise, thermal, or other unwanted effects before storage, and make data interpretation easier, faster, and more accurate. Diagnostics convert abstract data signals into useful information about the structural response and conditions [11].

\section{Modern Dam Monitoring Systems and Examples}

Great progress has been done in the world today in the field of seismic monitoring of dams. The high cost of seismic monitoring systems of large strategic dams utilizing available modern technologies of recording and transmitting data to remote control centers is justified by the great value attached to these dams. Two cases of such progress are presented in the following.

\subsection{Old Aswan Dam and High Aswan Dam, Egypt}

An example of advanced monitoring systems applied to Old Aswan and High Aswan Dams in Egypt is given here to show the type and level of technological sophistication reached in the field of seismic safety monitoring of dams and to explain the techniques used.

The contract was awarded in 2011 to Ref Tek, a division of Trimble Geospatial for the design, supply and commissioning of a strong motion instrumentation network for both dams. The network was installed with the support of Noor Scientific \& Trade Co. and completed in 2013.

The Old Aswan Dam is a $54 \mathrm{~m}$ high and $1900 \mathrm{~m}$ long gravity buttress dam whose construction began in 1899 and it was completed in 1902. The buttress sections accommodate numerous gates, which were opened yearly to pass the flood and its nutrient-rich sediments, but without retaining any yearly storage. The dam was constructed of rubble masonry and faced with red ashlar granite. The design also included a navigation lock of similar construction on the western bank, which allowed shipping to pass upstream as far as the second cataract, whereas portage overland was previously required. When constructed, the Old Aswan Dam was the largest masonry dam in the world; nothing of such scale had ever been attempted. The initial construction was found to be inadequate for development needs, and the height of the dam was raised in two phases; five meters between 1907-1912 and nine meters between 1929-1933. Generation of electricity was added. The Old Aswan Dam supports now two hydroelectric power plants, Aswan I (1960) and Aswan II (1985-1986). Aswan I contains 7 X 40 megawatts generators with Kaplan turbines for a combined capacity of 280 
megawatts and is located west of the dam. Aswan II contains 4 x 67.5 megawatts generators for an installed capacity of 270 megawatts $(360,000 \mathrm{hp})$ and is located at the toe of the dam.

When the dam almost overflowed in 1946, it was decided to build a second dam, which is the High Aswan Dam in the upstream rather than raise the dam for the third time, see Figure 5. With the construction of the High Aswan Dam upstream, the Old Dam's ability to pass the flood's sediments was lost, as was the serviceability provided by the navigation lock. Aswan High Dam, is a huge rockfill dam, located on the Nile River north of the border between Egypt and Sudan. The Dam, known as Saad el Aa'li in Arabic, was completed in 1970 after ten years of work.

The dam is a massive structure containing 18 times the material used to build the famous Pyramid of Cheops at Giza. It is 3,600 meters long 980 meters wide at the base and 111 meters high above the river level. Figures 6 and 7 show some views of the dam and the power station.

The two Aswan Dams benefit Egypt by controlling the annual floods on the Nile River thus preventing the damage which used to occur along the flood plain. The High Aswan Dam increased cultivable land by $30 \%$ and provides about a half of Egypt's electrical power. The total installed capacity in its power station is 2100 MW provided by $12 \times 175$ MW Francis type turbines.

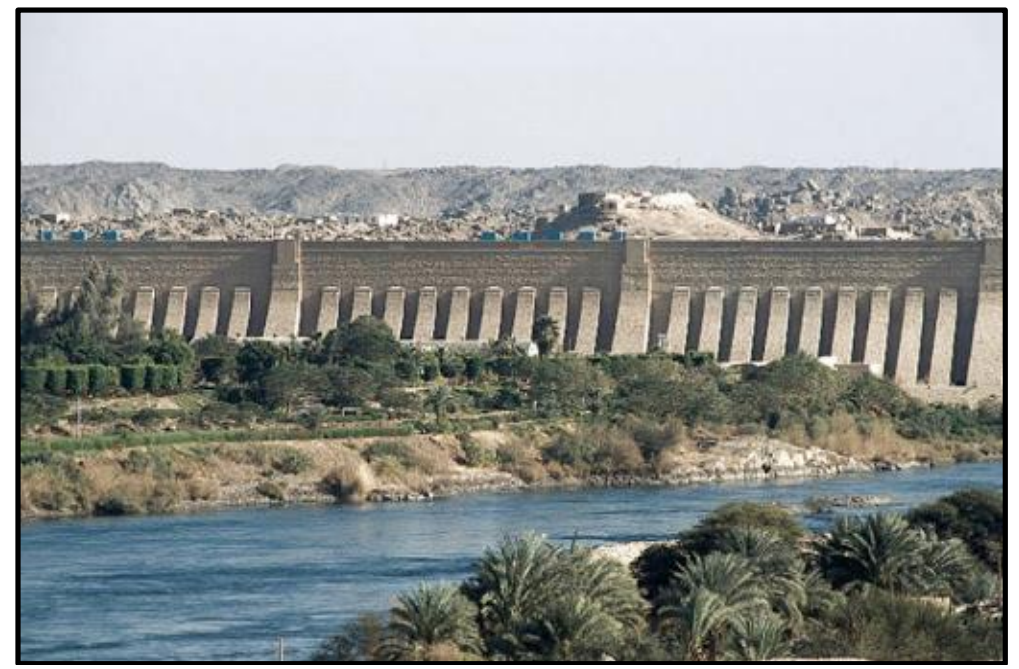

Figure 5: Downstream view of the old (low) Aswan Dam [13]. 


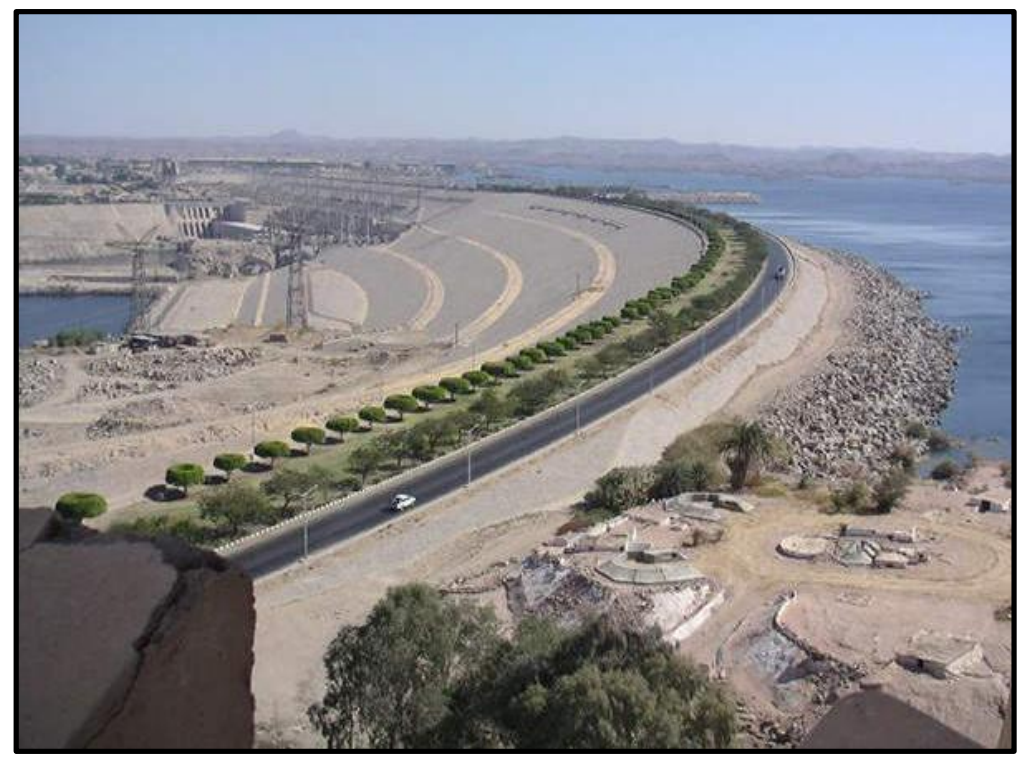

Figure 6: An overview of the High Aswan Dam (Water Technologies) [14].

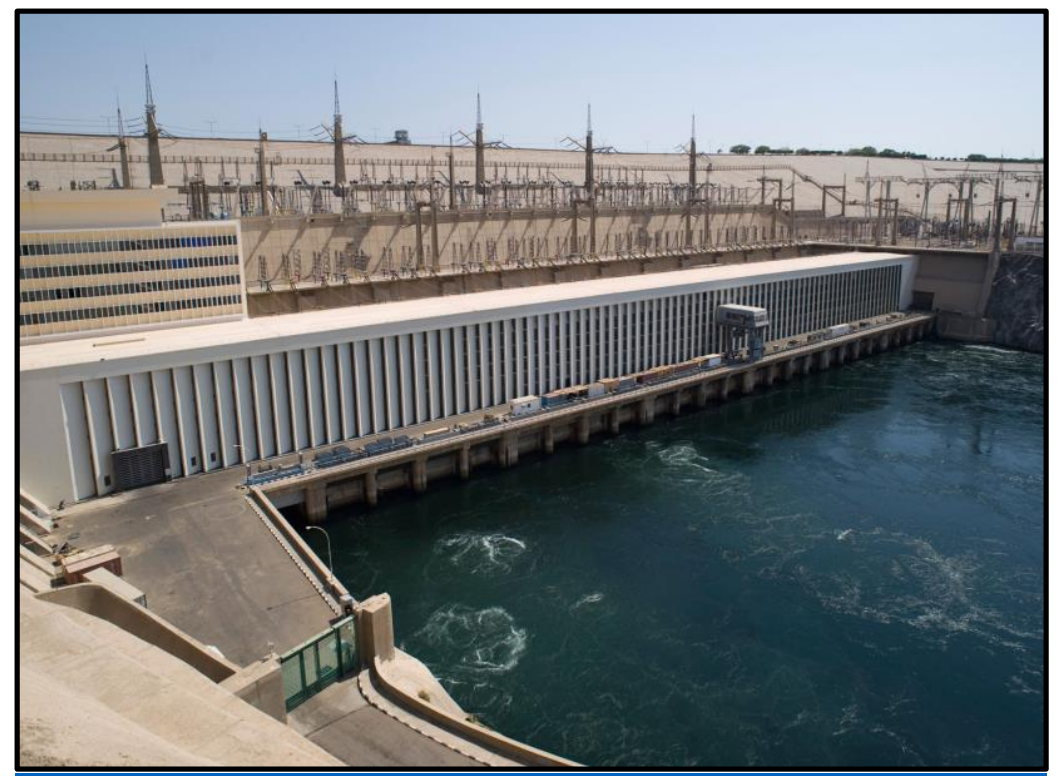

Figure 7: Downstream view of the power station at High Aswan Dam [15].

The $\mathrm{a} / \mathrm{m}$ information is given to show the extreme importance and strategic nature of these infrastructures; this led the Egyptian National Research Institute of Astronomy and Geophysics (NRIAG) to agree with the Aswan and High Dams Authority (HADA) that an array of strong motion accelerographs should be installed to record seismic activity in the area, in order to better monitor and study its effect on the structures of the two dams.

NRIAG criteria for the strong motion array consisted using the following: 
i) Remote and fixed strong motion accelerograph stations consisting of accelerometers and digital recorders,

ii) Communications network; and software to receive and analyze the seismic data.

Fort the High Aswan Dam, the instrumentation installed were five low noise, high resolution and strong motion recorders (Model 130-SMHR); four in the High Dam structure, and one (free field station) located on bedrock at the north side of the Dam base. The illustration in Figure 9 below shows layout of the array inside the dam. The High Dam has three galleries (tunnels) inside the Dam body. Each tunnel is about 1500 meters deep. The upper gallery contains two 130-SMHRs plus one at the entrance to the gallery, and the southern lower gallery has one 130-SMHR. The fifth 130-SMHR is externally located on the crest of the dam [16].

The 130-SMHR strong motion accelerograph, which combines the 130-01 broad band seismic recorder and an internal low-noise force-balance triaxial accelerometer, was the perfect fit for this application. It provides accurate and timely data and information for seismic events, including their effects on buildings and structures by employing modern monitoring methods and technologies. The 130-SMHR has advanced communications features including transmission control protocol/Internet protocol (TCP/IP) over Ethernet and Asynchronous Serial. An LCD continuously displays state-of-health and status information.

The 130-SMHRs installed inside the dam body are powered by 220VAC mains power. The free field station at the North side of the dam base and dam crest are supplied by a solar energy system. The diagram in Figure 8 illustrates the power and communication equipment at the entrance of the two galleries at the High Dam.

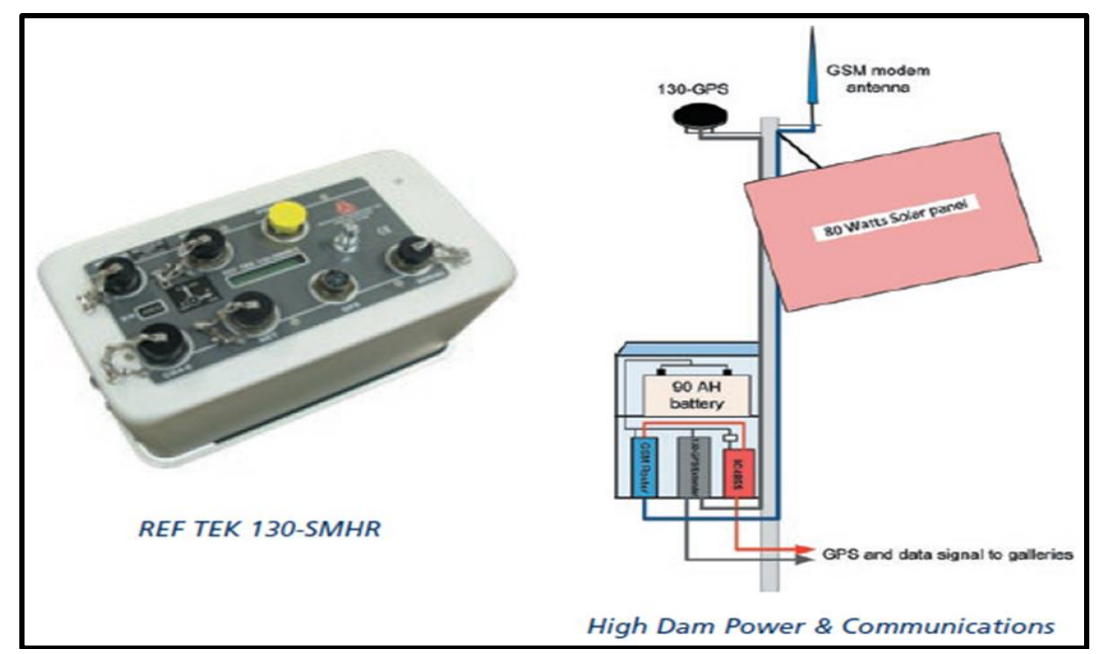

Figure 8: Illustration of the power and communication equipment at the entrance of the two galleries at the High Aswan Dam [16]. 
In the Old dam, and as this dam does not contain galleries, a total of five 130SMHRs were installed near the structure; one on bedrock on the ridge of the river; one at the Dam base; three at the Dam crest, with power supplied by a solar energy system. The illustration in Figures 9 and 10 shows the location of the instrumentation.

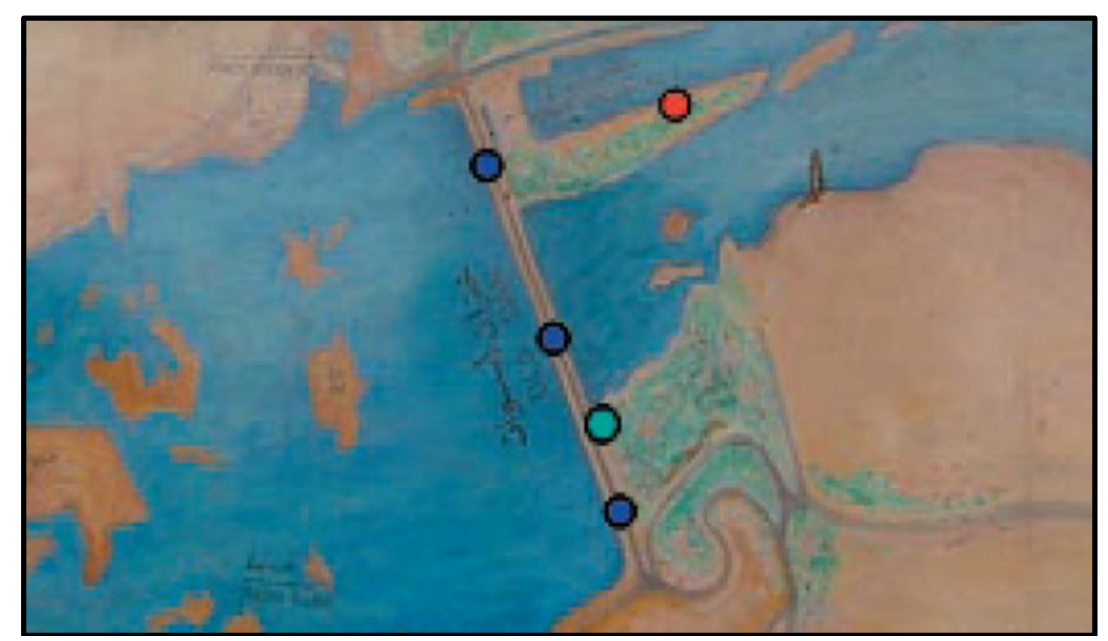

Figure 9: Old Aswan Dam instrumentation location [16].

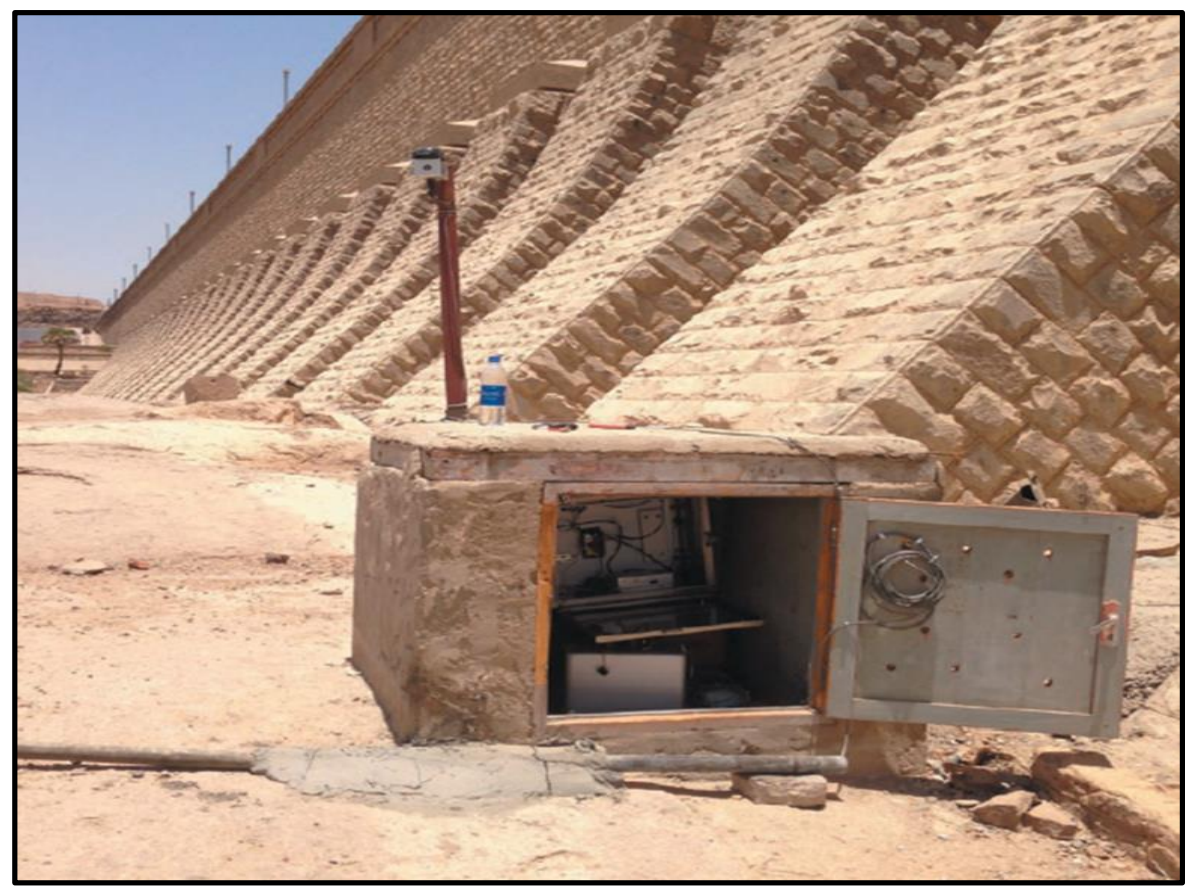

Figure 10: Old Aswan Dam field station [16].

As neither internet access nor reliable land lines are available to transmit data from the remote locations inside and outside of the two dams, Global System for Mobile telecommunication technology (GSM) is utilized for real-time data transmission. 
GSM is a proven technology for both temporary and permanent seismic telemetry network communication media. Net Module Wireless Routers are used to connect networks and sites, see Figure 11.

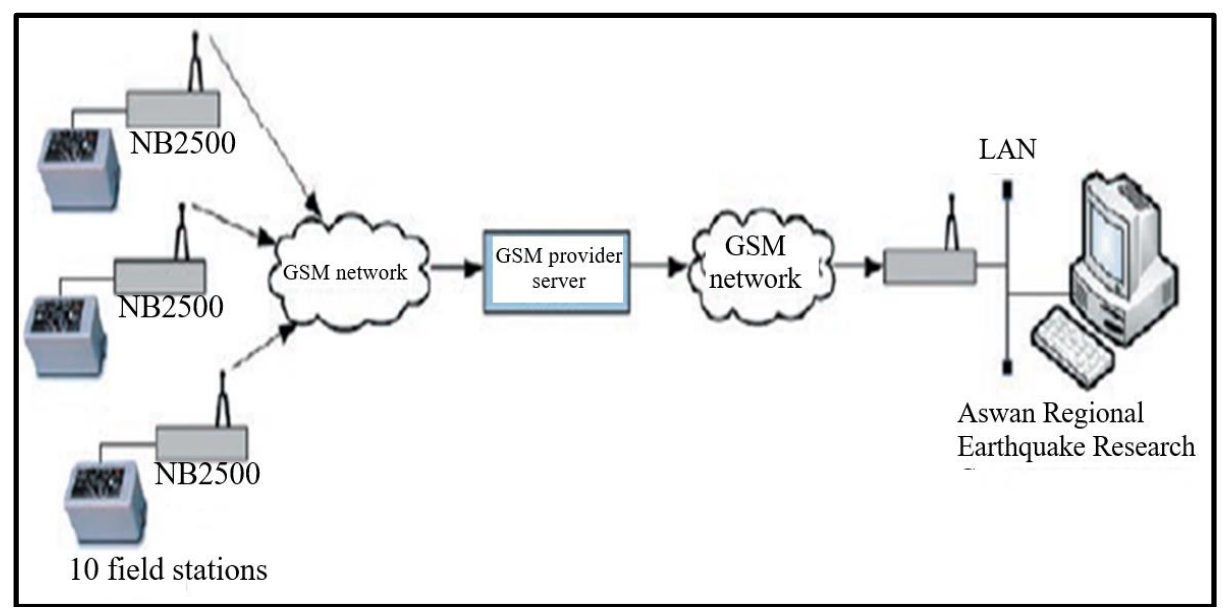

Figure 11: Illustration of GSM network [16].

All data transmitted from the strong motion instruments in the two dams are received by the established Aswan Regional Earthquake Research Center for further processing.

Data processing equipment supplied to the processing center included two servers equipped with advanced software for data acquisition, data analysis and data archiving. The acquisition software is capable of downloading data from remote instruments automatically on trigger, and on-demand. This software is also capable of configuring, controlling, synchronizing the 130-SMHRs remotely as well as monitoring the state-of-health. Mission critical computers and peripherals were installed at the processing center, as indicated in Figure 11.

The 130-SMHR has built-in hardware to support IP communications. The applications supported by them are an FTP server, a command server and an RTP protocol client.

Instrumentation of the Aswan dams has provided NRIAG scientists with invaluable information on the structure's response to seismic activity based on time-lapse observations and early warnings. Using the information, field crews are enabled to accomplish rapid deployment and prioritized inspections to address the need for safe and cost-effective operation of structures [16]. 


\subsection{Enguri Dam Monitoring System, Georgia}

A second example of dam monitoring system is cited from the dam monitoring of Enguri1 Dam. This dam, sometimes called Inguri Dam, is one of the highest concrete arch dams in the world which is located on the Enguri Rivers in Jvari, Georgia. It is part of the Enguri hydroelectric power station. The dam is $271.5 \mathrm{~m}$ high and $750 \mathrm{~m}$ long. Its crest has a length of $728 \mathrm{~m}$ and is $10 \mathrm{~m}$ thick. The power station is equipped with five Francis type turbines, $275 \mathrm{MW}$ each. Construction of the dam started in 1971; power station became partially operational in 1978, and it was completed in 1987. Repairs and refurbishment at the Enguri dam took place in 1999, and in 2011 work began to complete the rehabilitation and to ensure safe water flow towards the black sea. The Enguri dam was listed as cultural heritage of Georgia in 2015, Figure 12.

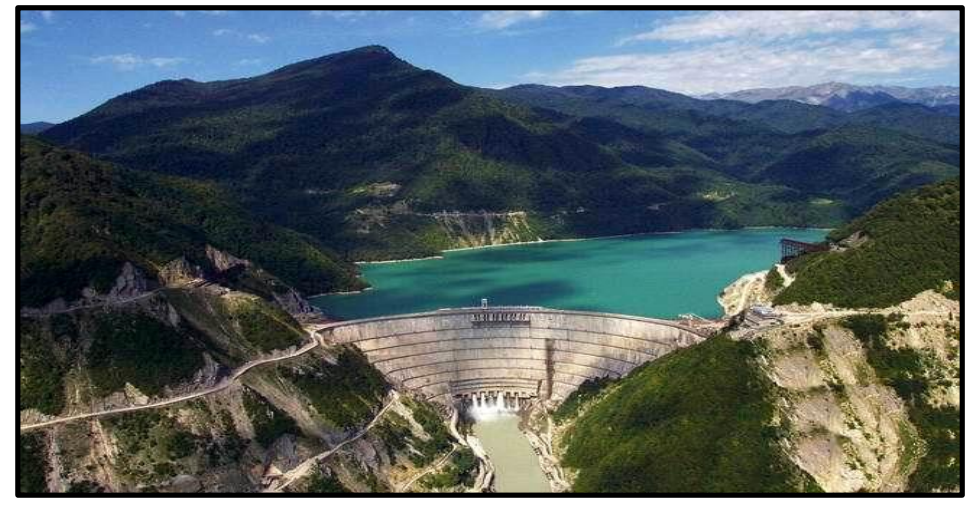

Figure 12: View of Enguri Dam, Georgia.

Georgia is situated in the Caucasus, which is one of the most seismically active regions in the Alpine-Himalayan collision belt. Historical analysis shows that it is a region of moderate seismicity and that strong earthquakes have occurred here in the past, including a 7.0M earthquake in the region of Racha in 1991, which killed 270 people.

The scope of the Enguri Dam seismic instrumentation project was installing dam monitoring system to record seismic motions and other ambient dynamic activity in order to continuously monitor dam structural safety within the context of a safe operating dam environment [17].

The solution was to install 10 (AC-63) force balanced accelerometers, 10 (GSR-18) strong motion recorders, an interconnecting cabling and modem system (GRX- ICC interconnection set), and a central processing system center with processing and reporting software, Figure 13. 


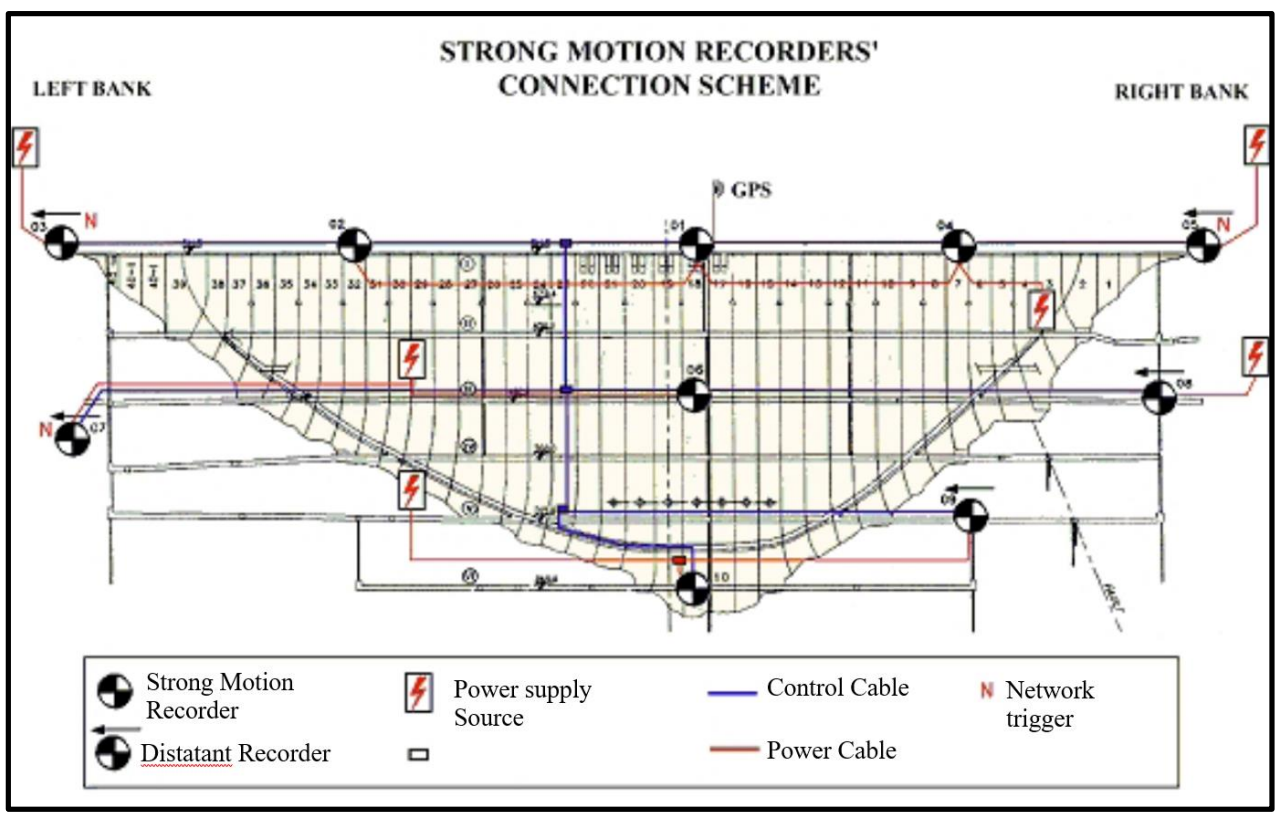

Figure 13: Strong motion recorders connection scheme [17].

Once the data has been processed, it is assessed and compared as the dam behavior against seismic design criteria applicable to dam operation. The project facilitated the development and improvement of dam emergency and safety measuring equipment within the context of increased awareness and contributed to the regional data management systems. Note that the instruments models cited here belong to instrumentation manufacturer and developer GeoSig, Switzerland.

\section{Dams Response to PGA During Earthquakes}

Damages sustained by dams in response to strong motion acceleration, measured at their sites, depends on type of the dam, whether concrete or earthfill, its height, its design, and the previous seismic history of the dam. As some damages may tend to accumulate due to recurrent events which tend in earthfill dams to change dam material's properties.

The main objective of seismic instrumentation of dams is monitoring their behavior when an earthquake occurs and recoding their response. The other important use is to compare recorded PGAs with those assumed for the design and examine ways of improving dams`safety; if the recorded values exceed the design assumptions.

The intensity and duration of ground vibration that a dam can tolerate without experiencing damage are quite variable. The physical factors that create such variation in dams when subject to earthquake ground vibration are; material used, its density and water content. Not only does physical property variability create problems, but also the parameters that best describe the necessary intensity of ground motion to create structural damage. These parameters include the maximum displacement, maximum particle velocity, maximum acceleration, and the natural 
frequency of the dam body. In this respect each dam is unique case which means that it should be instrumented as it stands.

Seismic instrumentation is used to record the response of a structure, foundation, and abutments to seismic events. One of the specific applications of the acquired measurements is to furnish data to decide if the structure will continue to function as intended, and for the purpose of evaluating its behavior in such an event verifying design assumptions made for such case. Sustained damages observed in dams after an earthquake may be correlated with the recordings of the seismic instruments installed at or near dam sites. This correlation can help for better assessment of design requirements to resist the ground shacking that may be caused by similar earthquakes in future planned dams. Normally, measured parameters by seismic instruments are the maximum ground acceleration (PGA) which is caused by an earthquake of magnitude (M) whose focus is at known distance from the dam, and moreover, the time history and frequency of such ground vibration.

Ground shaking during an earthquake can cause various kinds of damages. This matter depends on the previously mentioned parameters in addition to the type of the dam itself and the seismic criteria used for its design.

In embankment dams, damage may appear in the form of settlements which can reduce freeboard, and deformations of the side slopes in addition to various types of cracking with various degrees of seriousness and extent leading to increased seepage. Liquefaction of the dam or its foundation materials is another possibility which depends on the type of these materials and their degree of saturation and the intensity of ground shacking.

In concrete dams, earthquake ground vibration can cause cracking of the structure, liquefaction of the foundation, structural movements and deformations, settlements, seepage and piezometric level rise in dam foundations leading to uplift pressure increase.

For the purpose of illustration of the embankment dams' response and possible damages due to measured peak maximum acceleration (PGA), examples are presented of embankment dams and concrete dams are presented in paragraphs 5 and 6 respectively.

\section{Embankment Dams Response to actual PGA During Earthquakes}

Three examples of embankment dams' response to actual PGA during Earthquakes are presented; two are for rockfill dams, and one for concrete faced rockfill dam. It must be stressed that no dams of the same type will respond in similar manner under seismic ground shacking; as this depends on the characteristics of the earthquake, its focal length and the geology and topography of the terrain, in addition to the design of the dam and the properties of its materials. It is necessary, however, to study as many cases as possible to draw general conclusions of the most probable type of damage to be expected and take necessary precautions. 


\subsection{Matahina Dam Case (1987), New Zealand}

Matahina Dam is a large embankment rockfill dam which was shaken by Edgecumbe earthquake (M6.3), New Zealand on May 2, 1987. The earthquake had caused a peak ground acceleration of $0.33 \mathrm{~g}$ at the base of the dam and triggered subsidence or settlement at the crest, revealing and boosting internal erosion. The dam response was recorded by five strong motion accelerometers and a maximum crest level acceleration of $0.42 \mathrm{~g}$ was measured. The rockfill at dam crest settled by $100 \mathrm{~mm}$ and the dam moved by $250 \mathrm{~mm}$ downstream generating deformation of the dam shoulders.

The earthquake occurred near the town of Edgecumbe. The dam is located on the Rangataiki River about $23 \mathrm{~km}$ south of the main shock epicenter and $11 \mathrm{~km}$ from the main surface faulting, Figure 14 [18, 19].

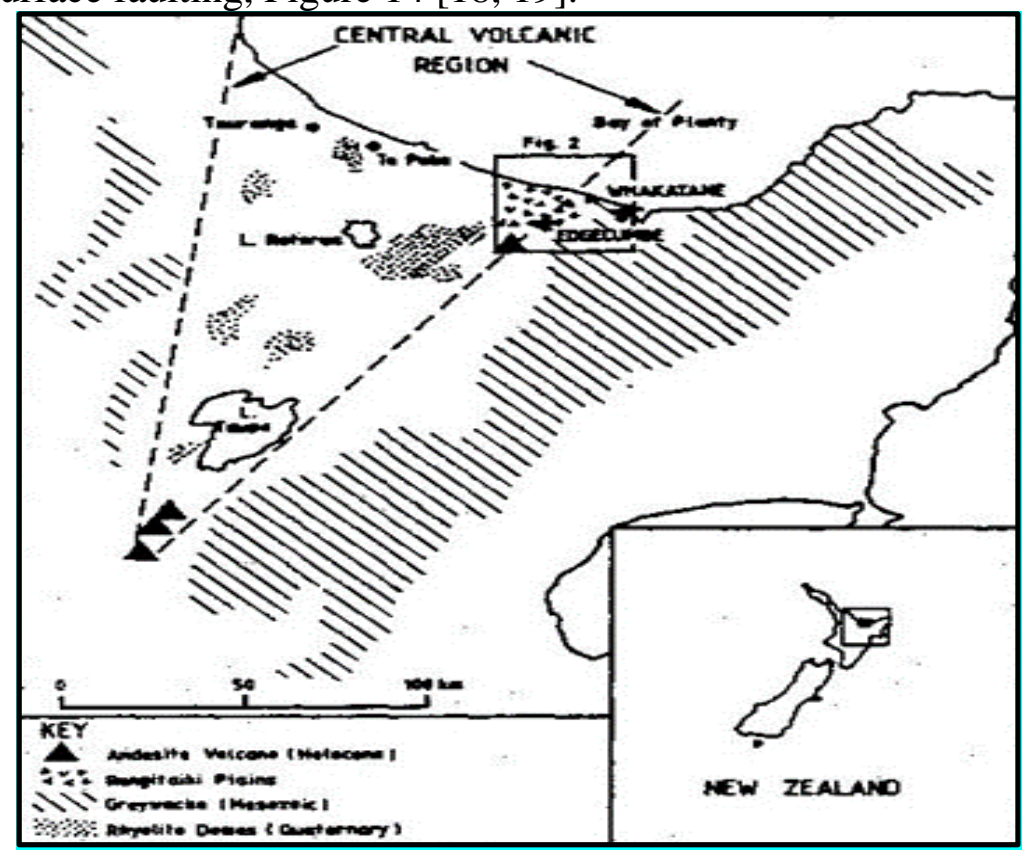

Figure 14: Regional geology; Matahina Dam [19].

In the two weeks preceding the main event, there were earthquake swarms in the region; these are culminated in the main shock at $00.01 \mathrm{hr} 42 \mathrm{~m} 34 \mathrm{~s}$ on 2 March 1987 UT. The epicenter location was $8 \mathrm{~km}$ NNW of Edgecumbe, Figure 14 and Figure 15 , and the focal depth was estimated to be $12 \mathrm{~km}$. The magnitude of the main shock was 6.3 .

A foreshock and four aftershocks had magnitudes of over 5.0 with epicenters within a few kilometres of the main shock. The accelerometer at the base of the dam recorded M5.2 foreshock, the M6.3 main shock and the largest aftershock, the M5.5 event 8 minutes after the main shock. The transverse (upstream-downstream) acceleration, velocity and displacement record from the base of the dam and the 5\% damped acceleration response spectra are shown in Figure (15a). The El Centro 1940 (N-S) response spectra is shown for comparison Figure (15b). 


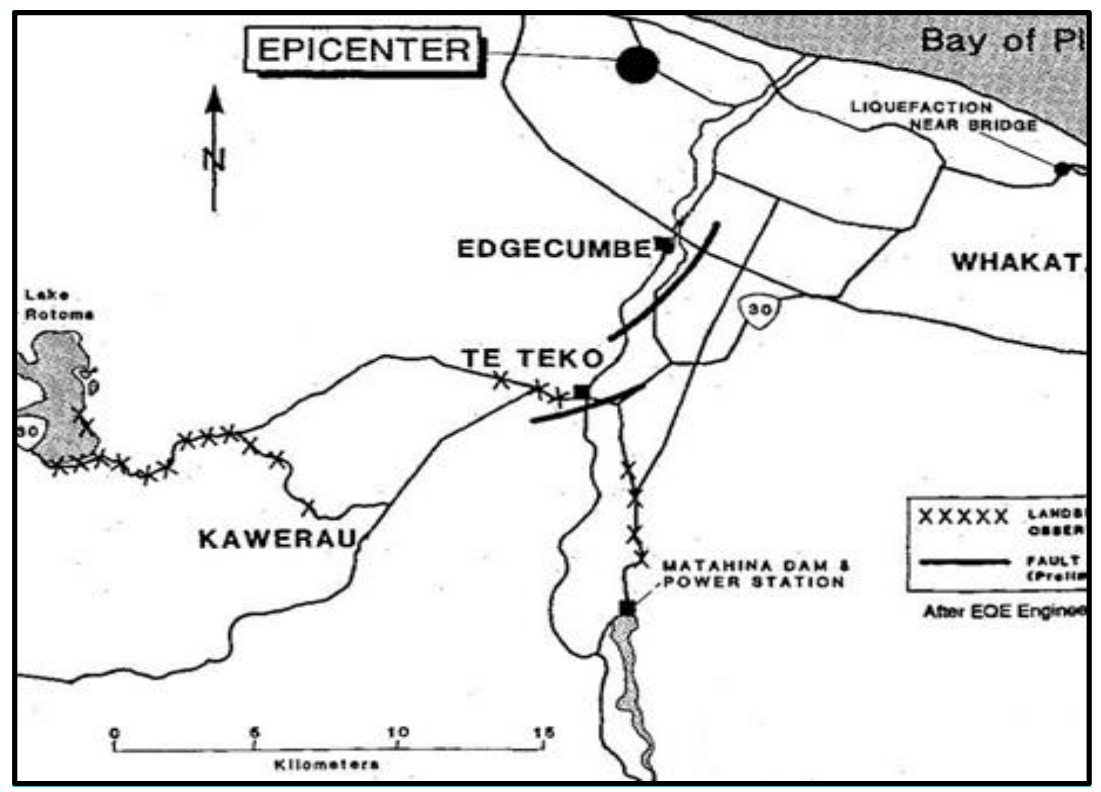

Figure 15: Location of Fault Rupture [19].

A87085D2 MATAHINA DAM D (BOTTOM CENTRE) COMPONENT NO7W

BAY OF PLENTY EARTHQUAKE 1987 MARCH 020142 UT

BAND-PASS FILTER TRANSITION BANDS ARE 0.100-0.250 HZ AND $24.5-25.5 \mathrm{HZ}$

a PEAK VAALUES: acceleration $2361 \mathrm{~mm} / \mathrm{s} / \mathrm{S}$, velocity $-216.5 \mathrm{~mm} / \mathrm{s}$, displacement $-90.56 \mathrm{~mm}$

$$
\text { : }
$$
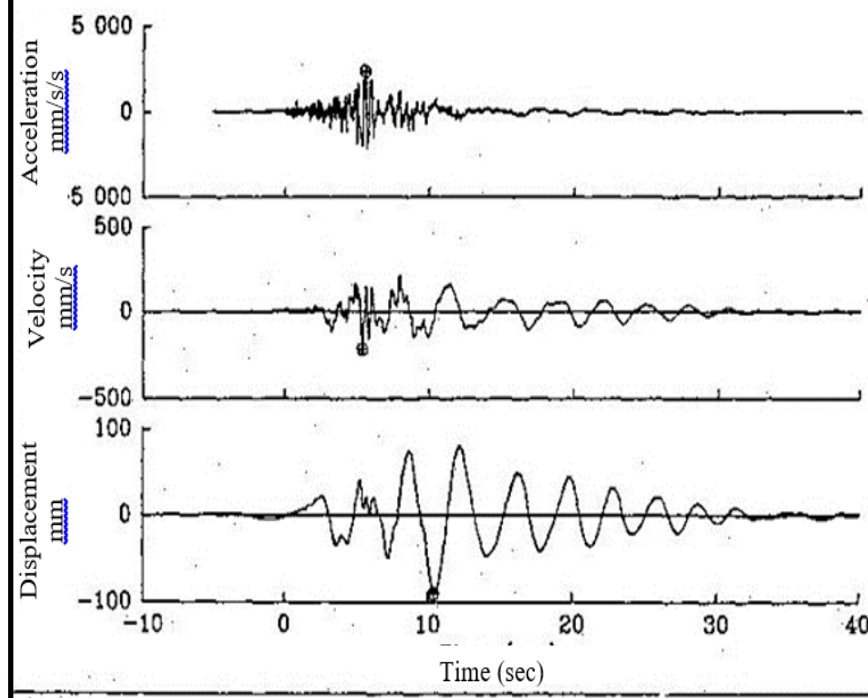

A87085D2 MATAHINA DAM D BAY OF PLENTY EARTHQUAKE $1987 \mathrm{MARCH}$ 02014 FOURIER AMPLITUDE SPECTRUM OF ACCELERATION

Peak spectral amplitude $=1.228 \mathrm{~m} / \mathrm{s}$ at 2.014

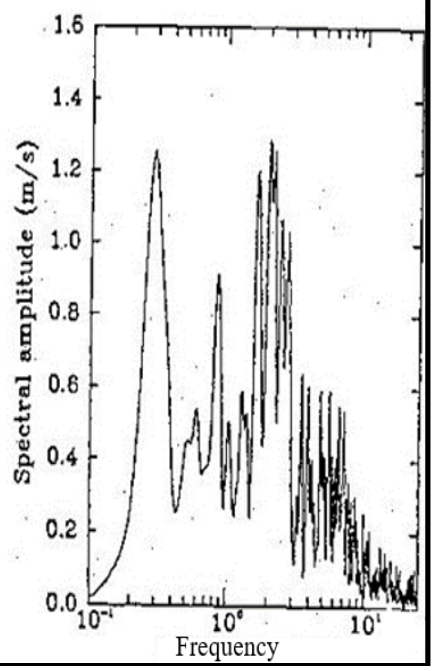

Figure 15a: Acceleration, velocity and displacement at the base of Matahina Dam [19]. 


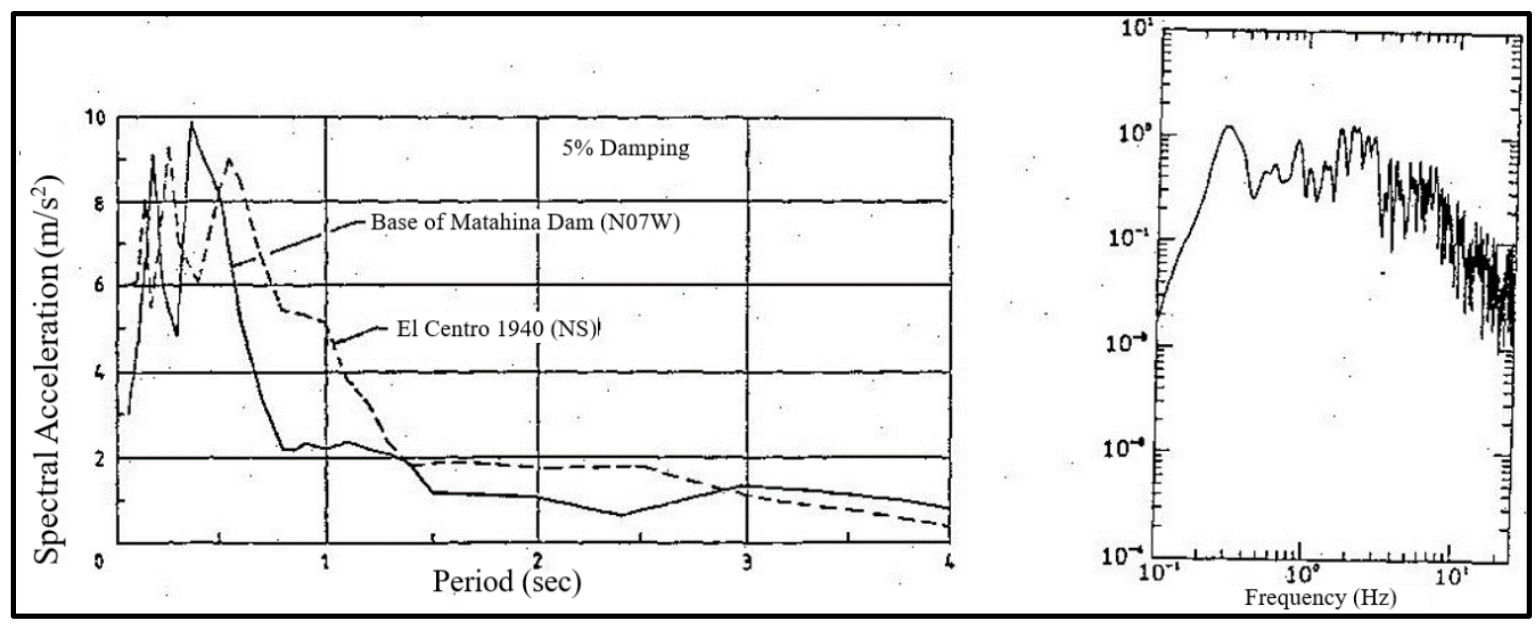

\section{Figure 15b: El Centro earthquake (1940) 5\% damped acceleration response spectra (for comparison) [19].}

The dam (Figures 16 and 17) stands $86 \mathrm{~m}$ high above foundation level and has a crest length of $400 \mathrm{~m}$. It has an upstream sloping core of moderate width. The core material is weathered greywacke with a low plasticity gravelly clay grading. The dam shoulders are of hard ignimbrite rockfill compacted by heavy tractor track rolling. The transition zones between the core and shoulders comprise the fines and softer stripping from the ignimbrite rock quarry.

There is a grout curtain forming a partial cutoff within the spur supplemented by two drainage drives. Seepage flows and groundwater levels are monitored.

Under seepage is controlled by a shallow cutoff below the core and a $30 \mathrm{~m}$ deep curtain of drain holes which discharge into an extensive drainage blanket. Flow from the drainage blanket is monitored by a weir located in the old river channel downstream of the dam.

The dam instruments include five strong motion accelerometers from which records of the foreshock and main shock were obtained. The extensive surface monument network had been resurveyed three weeks prior to the earthquake.

During lake filling in 1967, core cracking, leakage and internal erosion occurred above a step in the right abutment. High turbid leakage flows were observed at the drainage blanket monitoring weir. An erosion cavity was subsequently located downstream of the core. Repairs comprised a plastic concrete patch on the downstream side of the core backed by granular filter zones. The core was grouted with a cement bentonite mix and the lake refilled without further incident. 


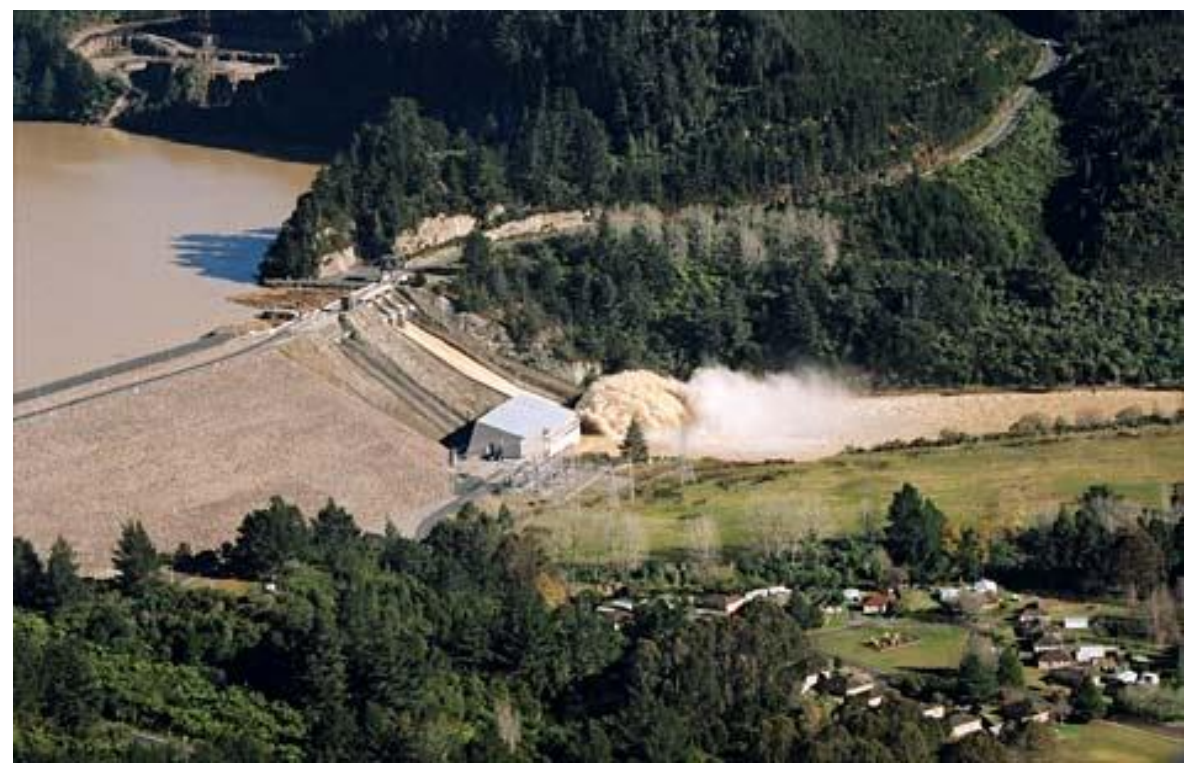

Figure 16: View of Matahina Dam [20].

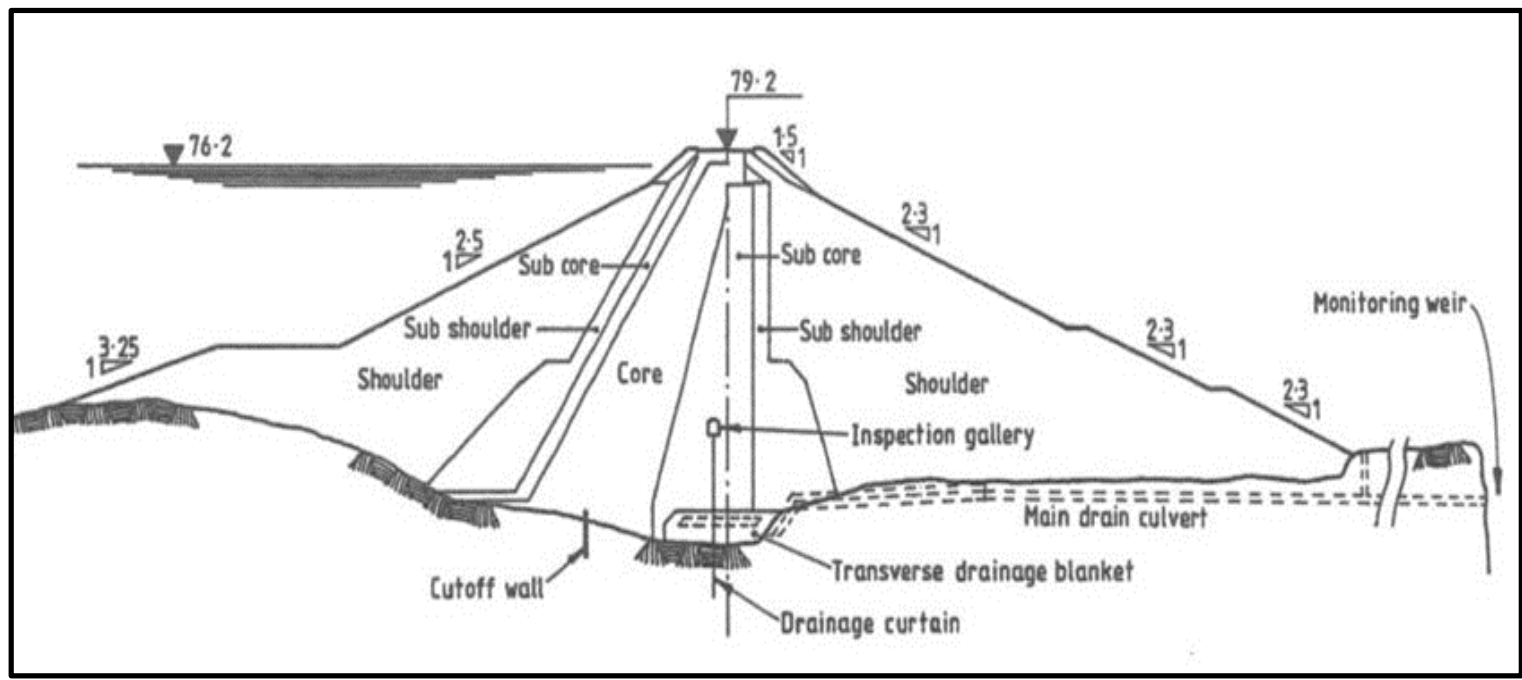

Figure 17: Cross section of the Matahina Dam [21].

Detailed inspection following the earthquake showed surface cracking and minor local settlements near the abutments, a turbid and increased drainage flow from the left abutment spur, a minor increase in flow at the drainage blanket weir, settlement and downstream displacement of the crest and large settlements in the upstream rock fill shoulder. Investigating the damages revealed the following: 


\section{i) Seepage}

It was observed during the period of lake drawdown following the earthquake. Flow from the drainage blanket weir increased from $701 / \mathrm{min}$ to $6301 / \mathrm{min}$. Four days after the earthquake flow from the weir ceased and it has flowed only intermittently since then. Investigations concluded that in the periods of low tailwater level flow from the drainage blanket leaks into the groundwater system downstream of the dam. The increase in flow after the earthquake was probably due to the increased tailwater level during drawdown and that increased leakage up to $20001 /$ min may not be detected during periods of zero weir flow, and no major dam leakage has occurred as a result of the earthquake.

Seepage flow from the left abutment rock spur which rose to four times the normal flow after the earthquake has continued to slow rise. This trend was continued to be observed and was closely monitored eight months after the earthquake.

\section{ii) Settlements}

Measured settlements of survey points are shown in Figure 18, which indicates the very small settlements of the left abutment spur and the much larger settlement of the dam immediately after the earthquake. Given the level of shaking, the settlements are not considered excessive, but they were viewed with concern because of the core cracking and erosion associated with lake filling.

Settlement of the dam continued for several weeks. During this time, the crest settlements were less than the rock fill settlements as would be expected. Measurements from the inspection gallery did not suggest significant foundation settlement, Figure 19. The long term settlement of the left abutment spur was unexpected, Figure 19. The results indicate a fairly uniform settlement without tilting. The settlement caused increased leakage into the powerhouse.

The upstream shoulder settlements were estimated. Settlements of $800 \mathrm{~mm}$ were typical. Subsurface sonar was used to check for evidence of under-water slope failure. There were no detectable scarps and it is considered that the settlements are simply the result of earthquake induced compaction of the rockfill.

\section{iii) Displacements}

The displacement of the downstream rockfill shoulder is shown in Figure 19. The maximum displacement of $253 \mathrm{~mm}$ compares with about $220 \mathrm{~mm}$ during the lake filling period.

The ratio of long term crest displacement/settlement (typically 2.5) is similar to that observed during the earthquake. 


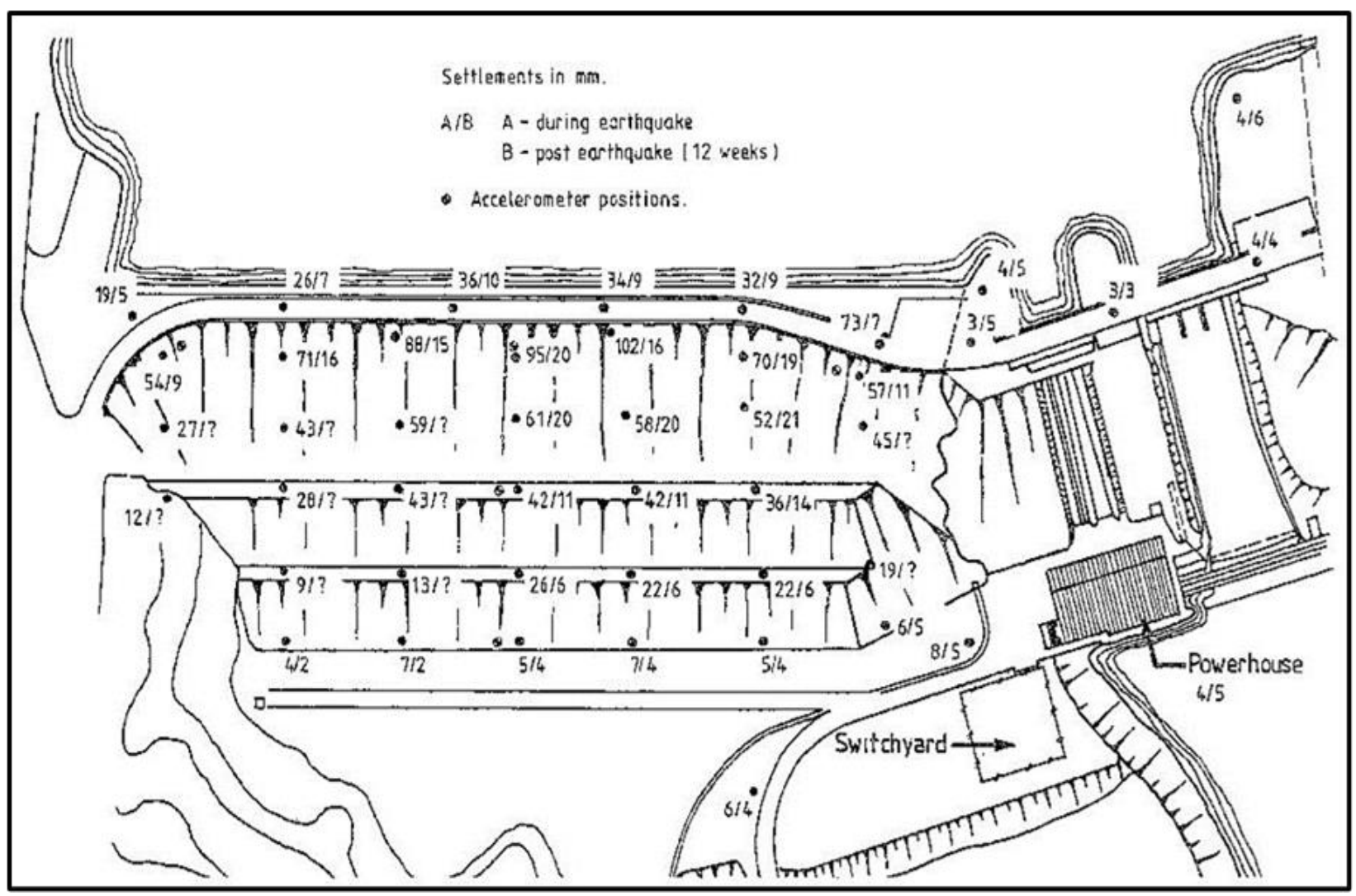

Figure 18: Settlements resulting from earthquake [21].

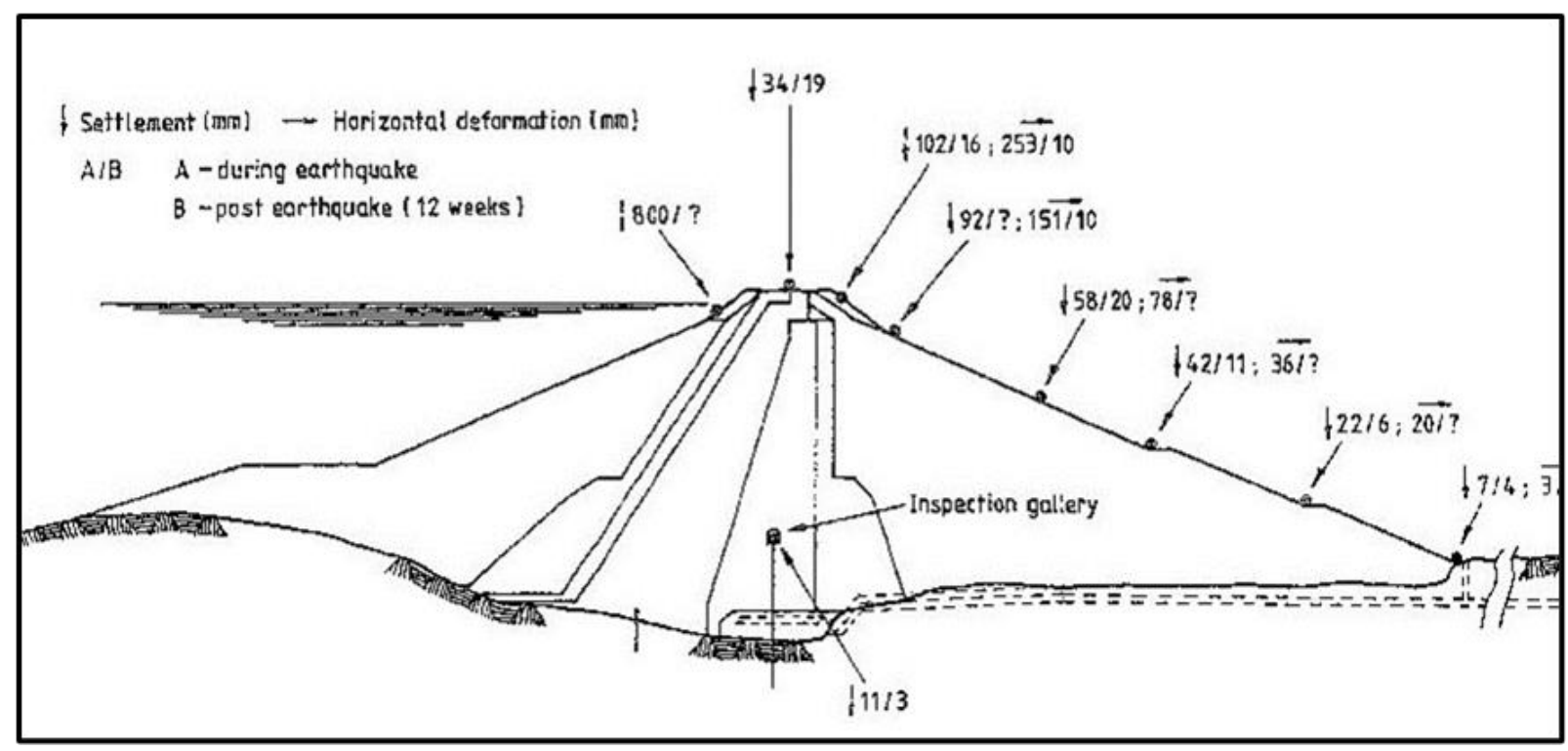

Figure 19: Deformations at the center of the dam [21]. 


\section{iv) Left abutment area}

Four inclined drill holes were drilled using air flushing. High water inflows were encountered downstream of the core of the dam. Caving areas were found in two holes. Twelve piezometers were installed and anomalously high pore pressures measured. Permeability's measured from falling head tests in the piezometers are at least 1,000 times higher than expected.

The results indicate that core cracking and erosion had occurred similar to that observed in 1967 on the right abutment. It is not known whether the defects were predating or postdate the earthquake. Intensive monitoring indicates that they are stable at present. Remedial measures were proposed and executed.

The dynamic behavior of the dam was studied based on the recordings of the five strong-motion accelerographs of which the dam was equipped with. These recorded the foreshock and the main shock and some of the aftershocks. Three of these instruments were sited across the crest, one at the center of the base of the dam and one at a mid-height rockfill berm. They recorded the peak accelerations shown in Table 1.

Table 1. Summary of the maximum accelerations measured on the transverse dam's centreline [21].

\begin{tabular}{|c|c|c|c|c|}
\hline \multicolumn{2}{|c|}{ Description } & \multicolumn{3}{|c|}{ Acceleration $\left(\mathbf{c m}^{2} / \mathbf{s}\right)$} \\
\hline \multicolumn{2}{|c|}{ Component } & Base & Midheight & Crest \\
\hline \multicolumn{2}{|c|}{ Vertical } & 1378 & 2018 & 3247 \\
\hline \multirow{3}{*}{ Horizontal } & Maximum & 3247 & 4680 & 4155 \\
\cline { 2 - 5 } & Transverse & 4366 & 3209 & 2824 \\
\cline { 2 - 5 } & Longitudinal & 4155 & 3427 & 2766 \\
\hline
\end{tabular}

The vertical base acceleration is amplified by a factor of over two at crest level. The horizontal crest components are amplified more in the transverse direction than in the longitudinal direction. An unexpected result is that the highest horizontal accelerations $(0.48 \mathrm{~g})$ are measured on the rockfill shoulder at the mid height of the dam which was subjected to further investigated.

\subsection{La Villita Dam Case (1985) Mexico}

La Villita Dam is a $60 \mathrm{~m}$ high zoned earth dam in Mexico with a crest about $420 \mathrm{~m}$ long, constructed on a $70 \mathrm{~m}$ thick alluvium layer. The dam was the principal component of a $304 \mathrm{MW}$ multi-purpose hydroelectric, irrigation and flood-control development. It was designed with symmetrical cross-section with a central impervious clay core, well graded filter and transition zones and compacted rock fill shells. The alluvial layer beneath the clay core was grouted below the dam, while there is also a $0.6 \mathrm{~m}$ thick concrete cut-off wall to control seepage through the alluvium below the dam. Figure 20a and 20b shows a schematic representation of the transverse cross section of the dam and a longitudinal section. Both sections show the location of three functioning strong motion accelerometers (C), (B), and (R).

Upstream and downstream faces slope at 2.5:1, horizontal to vertical. The dam crest 
is slightly concave toward downstream. La Villita Dam is constructed on up to70m thick, well-graded alluvial deposits from the Balsas River. The alluvium is composed of boulders, gravels, sands and silts which taper toward the abutments. The abutments consist of layers of andesite and andesitic breccias. A two-foot wide central concrete cutoff wall extends to bedrock across the entire dam foundation [22].

The dam was subjected to about 60 seconds of strong ground motion during the September 19, 1985 earthquake, which was recorded at the site, which was located at $75 \mathrm{~km}$ from the epicenter of the earthquake, and also on the dam.

The dam was well-instrumented. Five strong motion accelerometers, which include AR-240 and SMA-1 instruments, were installed at various locations within the dam and abutments. The dam was also equipped with 21 vertical and horizontal extensometers, 20 inclinometers, three horizontal rows of hydraulic levels and five lines of survey monuments, two on either side of and parallel to the crest, two near the upstream and downstream toes and one at about mid height of the downstream face. Forty-five piezometers, upstream and downstream from the concrete cutoff, monitor the effectiveness of this cutoff.

On September 19, 1985 earthquakes, the accelerometer at the center of the crest of the dam recorded a peak horizontal acceleration of $0.45 \mathrm{~g}$ and, on the following day, a peak acceleration of $0.16 \mathrm{~g}$ was measured during the strongest aftershock. Peak horizontal bedrock acceleration was recorded at $0.13 \mathrm{~g}$ for the main event and $0.04 \mathrm{~g}$ for the aforementioned aftershock. Post-earthquake seismological research studies showed that the September 19, 1985 earthquake resulted from two distinct bursts of energy lasting about 16 seconds each and separated by about 25 seconds. This dual rupture mechanism was more conspicuous on records from other strong motion stations closer to the epicenter than from the La Villita instruments. Bedrock records for the main event are shown in Figure 21. 


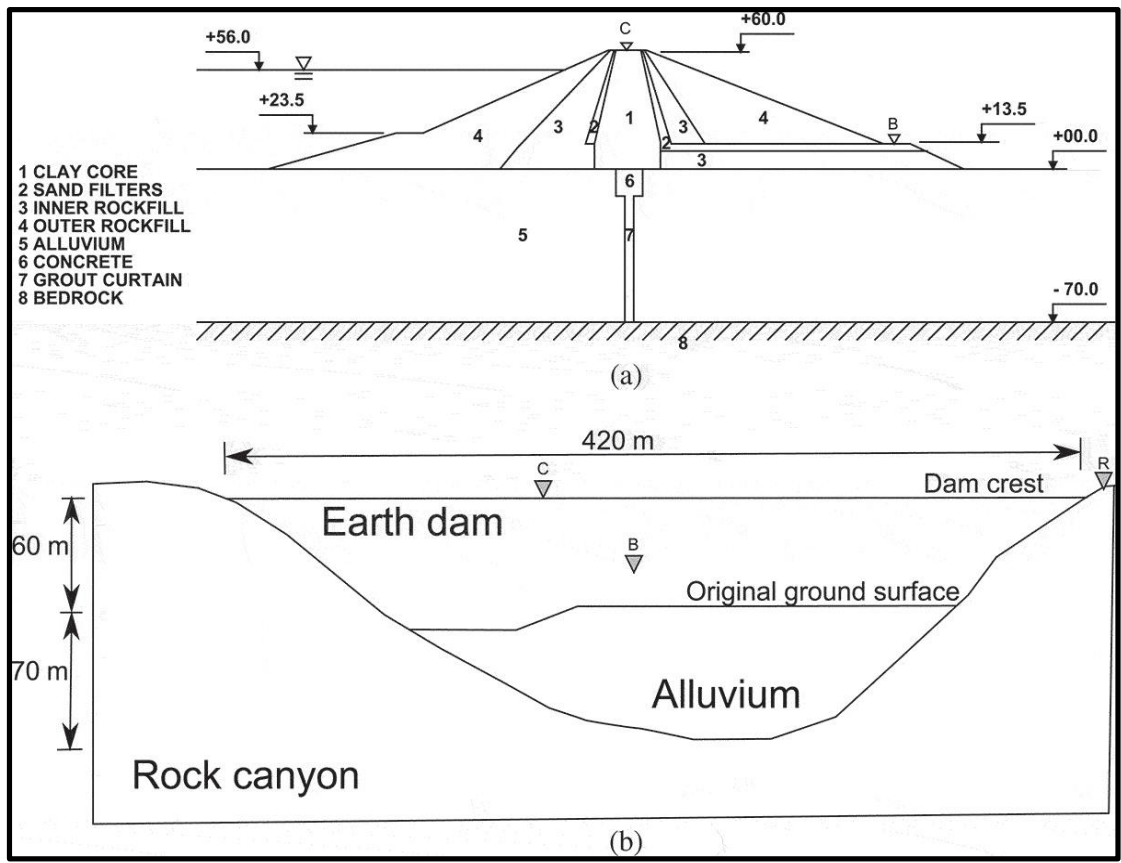

Figure 20: (a) Typical cross section; (b) Long section at La Villita Dam, showing location of the strong motion accelerometers (C), (B), and (R) [23].

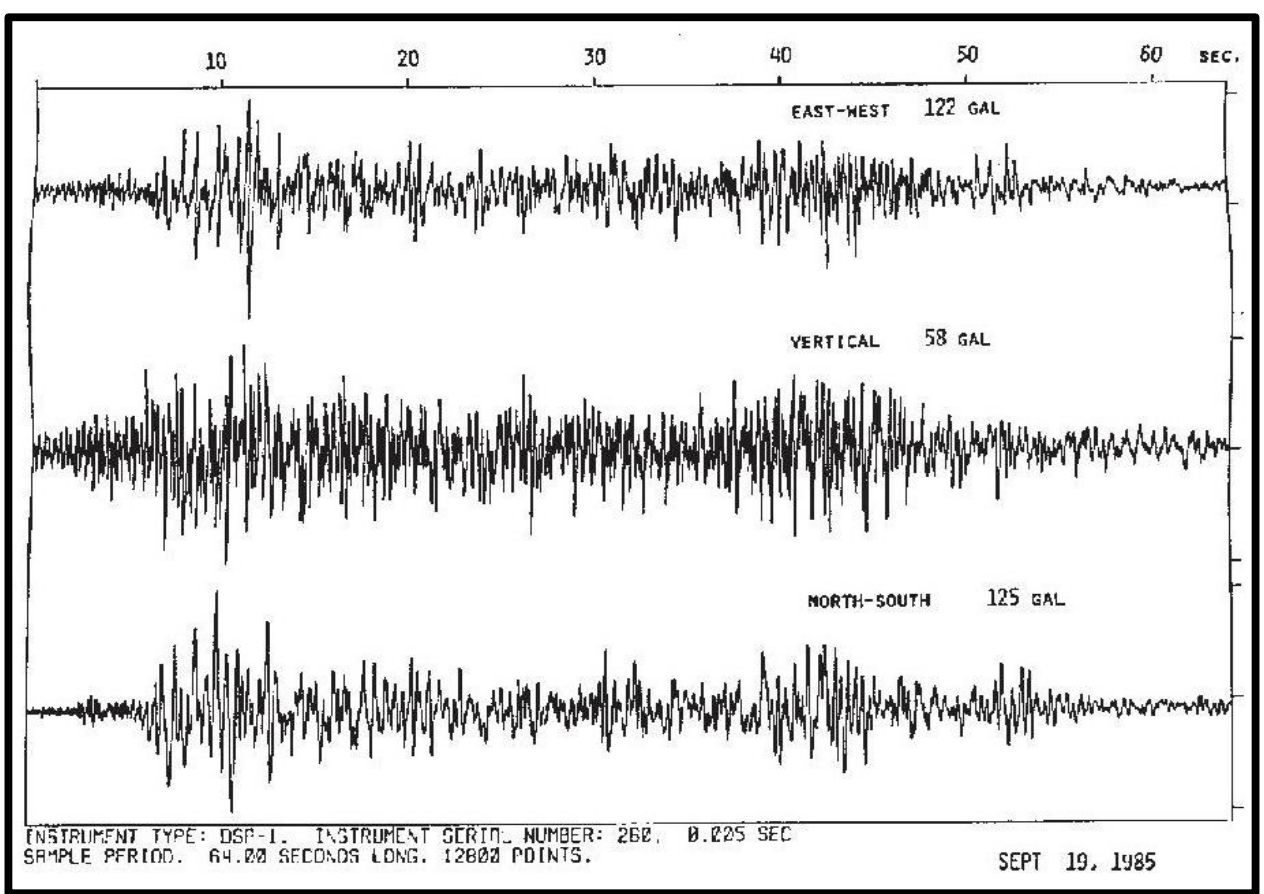

Figure 21: Bedrock acceleration records [22]. 
Damages to the dam was noticeable on the dam in the form of cracking, settlement and displacements, as follows:

\section{i) Cracking}

Two main systems of longitudinal cracks developed at the crest of La Villita Dam, parallel to its axis, some 16 feet away from the crest edges. These cracks formed along the buried shoulders of the central core and most likely resulted from differential settlement between the core and the adjacent filter zones. A 260- footlong crack, $1 / 4$ to 2 inches wide at the surface, formed along the upstream side of the dam crest. Vertical offsets of 2 to 4 inches occurred between the lips of the crack, the upstream side settling the most. On the downstream side, another major crack system appeared, about 1,000 feet long, 0.4 to 0.6-inch-wide, with vertical offsets ranging from 0.5 to 0.8 inch, the side toward the face of the dam being downthrown. Several other longitudinal cracks, up to two inches wide, but less extensive than the two principal crack systems, were also found. The most significant cracks did not reach the impervious core zone and were found to disappear below two-feet depth, except near the right abutment, where one of the cracks was delineated as a closed fissure through a clay lens embedded at about three-foot depth within the filter sands, Figures 22 and 23.

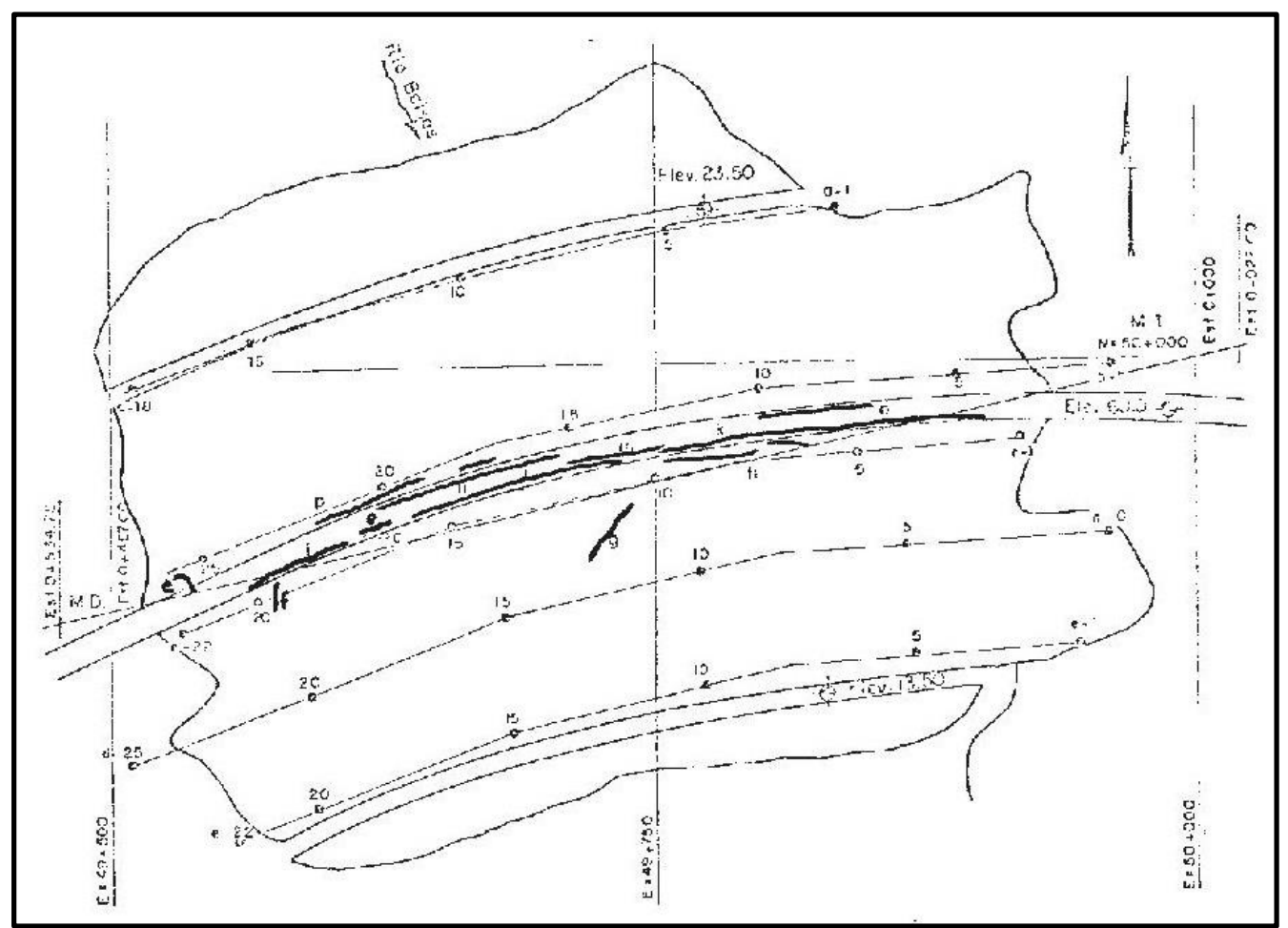

Figure 22: Crack Locations on La Villita Dam [22]. 


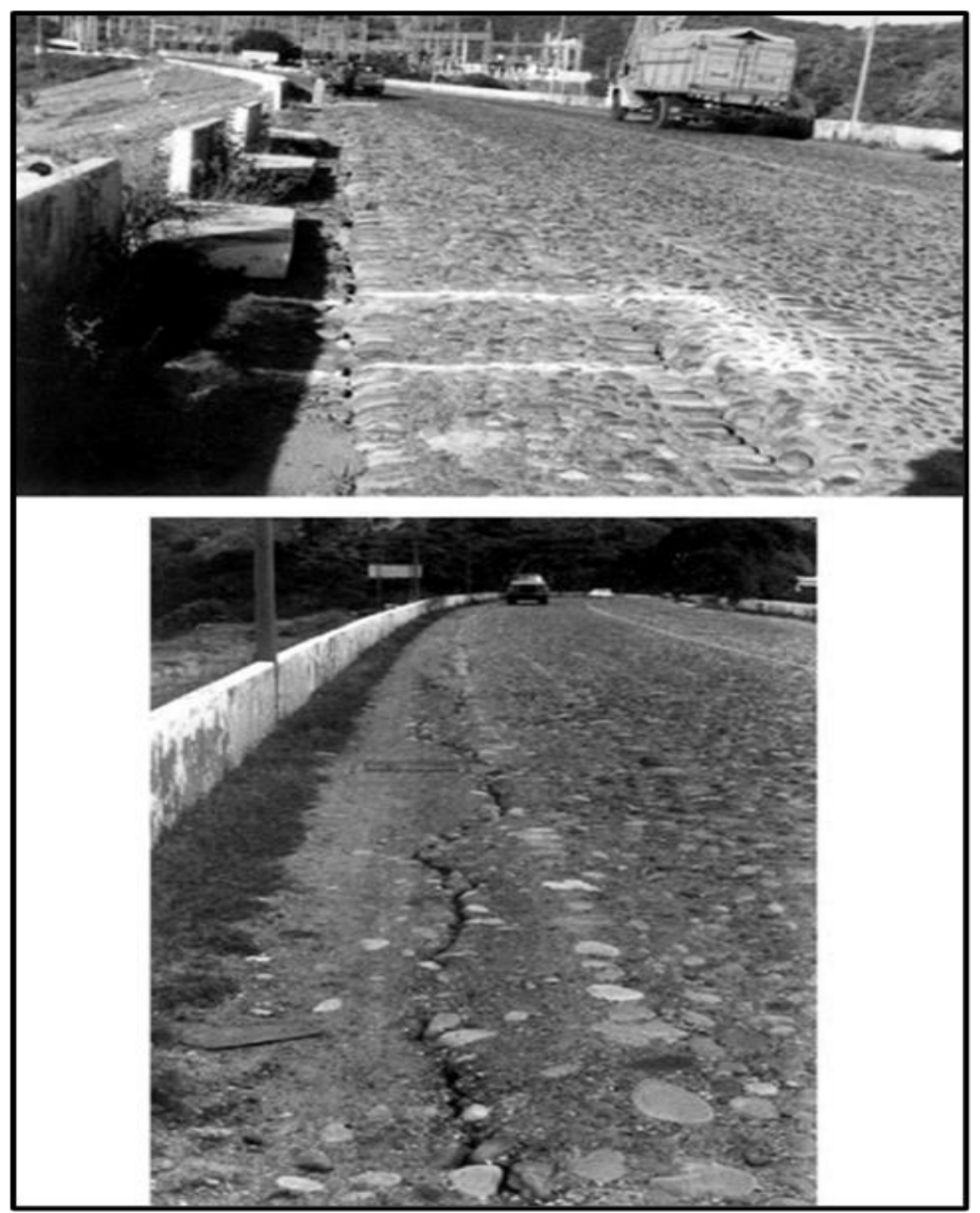

Figure 23: Photographs showing longitudinal cracking at dam crest [22].

\section{ii) Settlements}

Post-earthquake surveys showed that, in its central part, the dam settled between 20 and $32 \mathrm{~cm}$ on the upstream side and between 9.1 and $22 \mathrm{~cm}$ decreased in magnitude to near zero toward the abutments and seemed to be evenly distributed within the dam cross-section, rather than associated with distinct surfaces.

Figure 24 gives the accumulated settlement of the dam due to the earthquakes to which the dam was subjected in previous years. Earthquake-induced settlements have been found to exceed static postconstruction settlements and appear to increase in magnitude from one earthquake to the other, perhaps indicating a change in stiffness of the dam materials or a slow, cumulative, deterioration of part of the embankment. Inclinometer records confirmed that permanent deformations 
decreased in magnitude from crest to bottom of the embankment and did not involve the foundation materials.

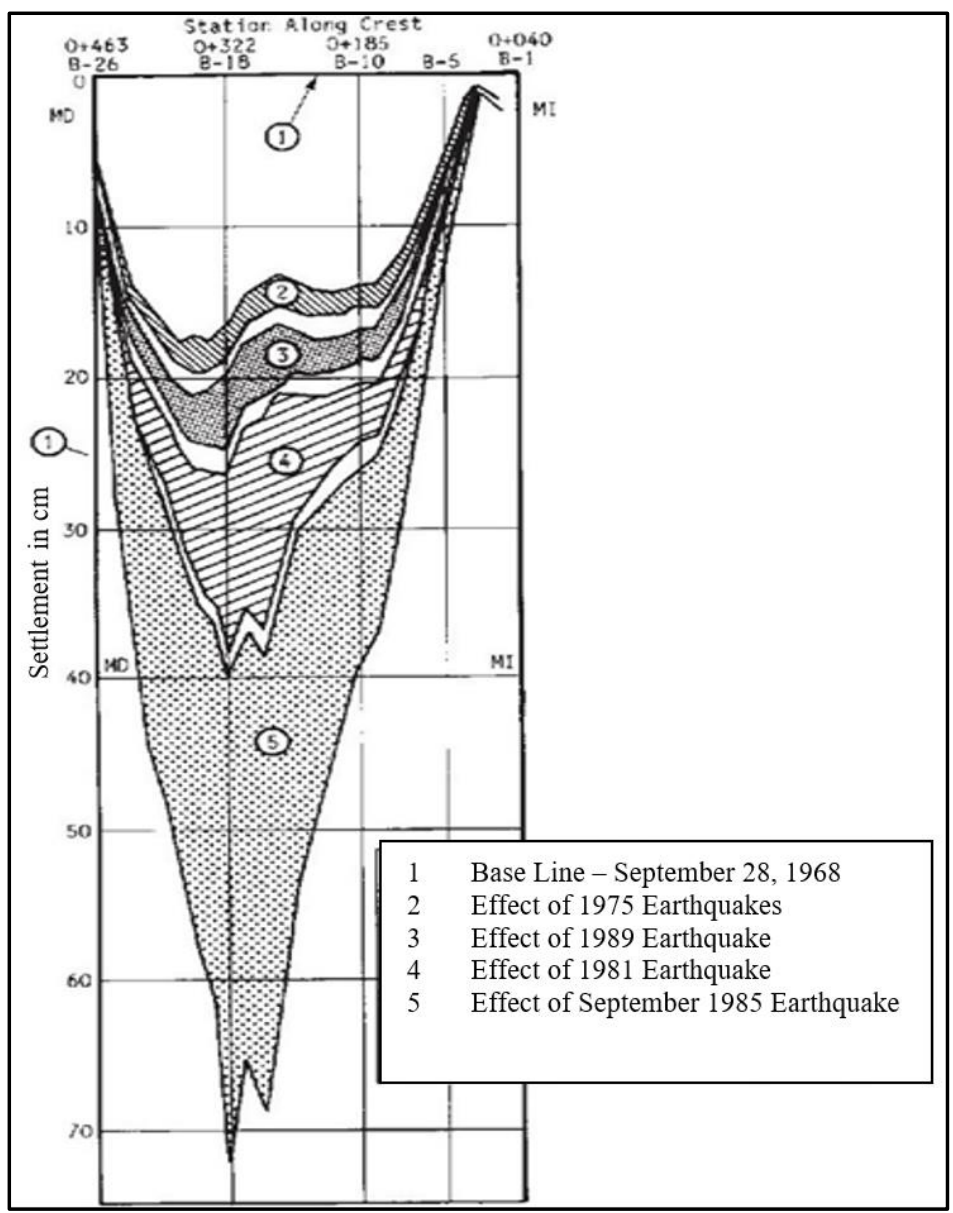

Figure 24: Historical crest Settlements record showing crest settlements from 1968 to 1985 [22].

Settlements were particularly noticeable at several piezometer locations, where the piezometer tubes which extend down $80 \mathrm{~m}$ to deep within the embankment remained in place, while their protective concrete boxes settled along with the face of the dam, Figure 25. 


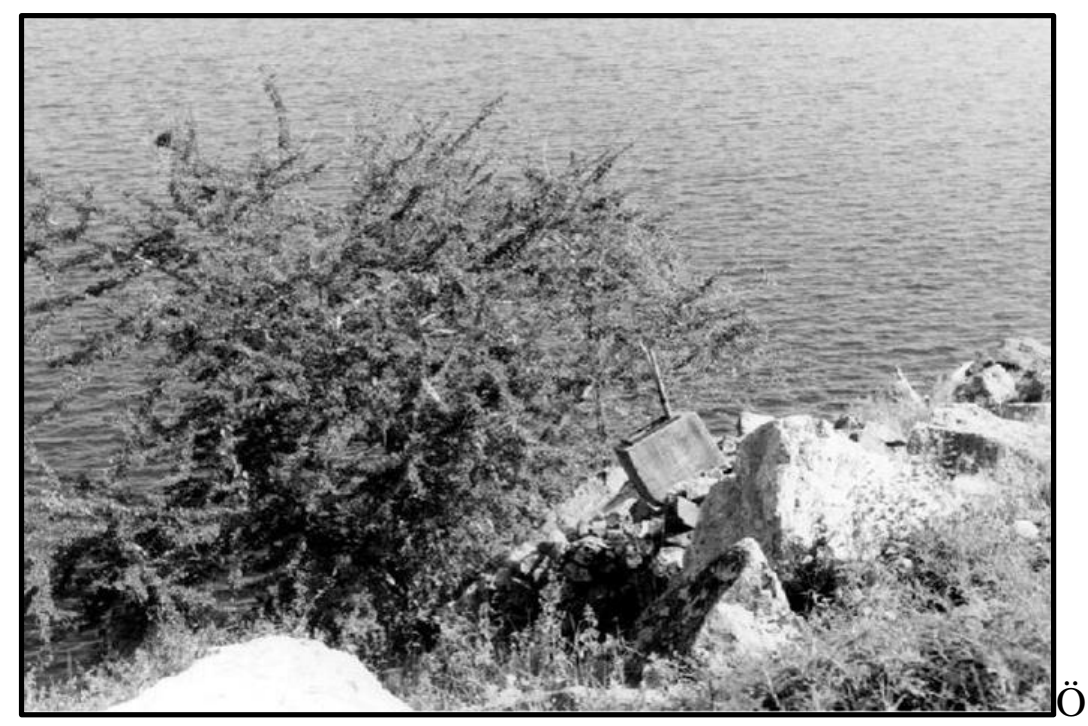

Figure 25: Settlement at piezometer box [22].

\section{iii) Displacements}

The downstream half of the dam moved horizontally up to $10 \mathrm{~cm}$ in the downstream direction and the upstream half up to $16.5 \mathrm{~cm}$ in the upstream direction. Downstream horizontal displacements were somewhat irregular, although generally more symmetrical with respect to the center of the dam than the upstream displacements.

These observed damages correlated well with the instrumentation and strong motion records. Survey monuments, inclinometers and extensometers were essential to provide detailed information on the earthquake-induced deformations of La Villita Dam. Of particular interest was the fact that the dam had previously been shaken by several significant earthquakes in the 12 years that preceded the 1985 event.

The dam was well instrumented, especially for strong motion accelerometers which proved their significant value by the records they provided; giving full picture of the dam response under large earthquakes.

It is interesting to note that the $148 \mathrm{~m}$ El Infiernillo earth core rockfill dam, which is located in the same area as La Villita Dam was also shaken by the same 1985 (M8.1) earthquake and the sequence of the five closely spaced events since 1975. The dam suffered also cracking and settlement problems, but the deformations remained small and consistent from one event to the next.

\subsection{Cogoti Dam Case (1943), Chile}

This dam is a concrete face rockfill dam built in 1938, it is located about 47 miles $(75 \mathrm{~km})$ from the City of Ovalle, Chile. The dam site is situated downstream from the confluence of the Pama and Cogoti rivers, and in a deep gorge naturally carved by the Cogoti River. Cogoti Dam, shown in plan and cross section in Figures 26 and 27 , has a maximum height of $85 \mathrm{~m}$, a crest length of $160 \mathrm{~m}$. The upstream slope averages $1.4 \mathrm{H}: 1 \mathrm{~V}$ and the downstream slope is about $1.5 \mathrm{H}: 1 \mathrm{~V}$. The dam is 
primarily used for irrigation purposes and impounds a reservoir of 148 million cubic meters capacity [24].

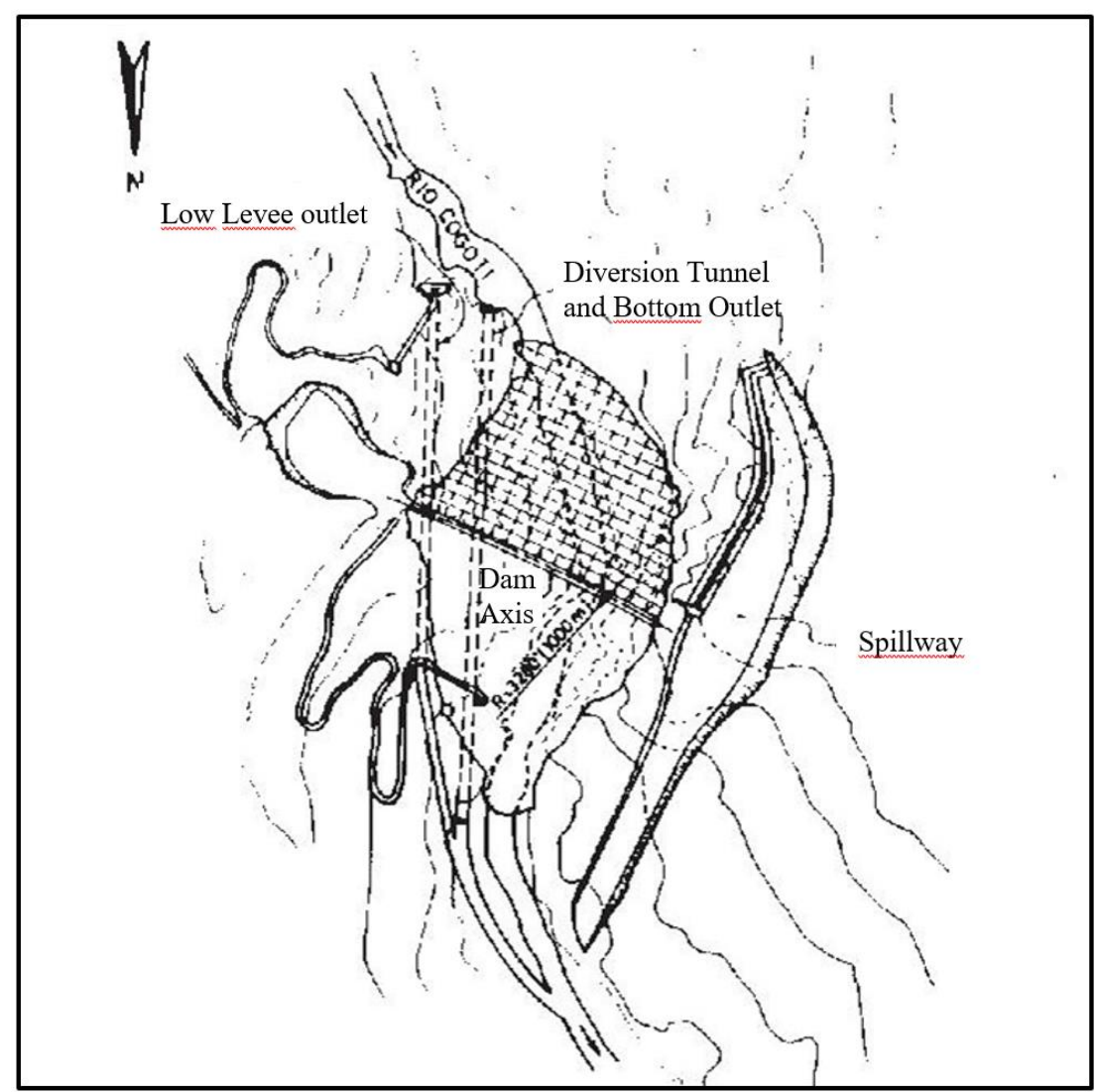

Figure 26: Site plan and layout of Cogoti Dam [24].

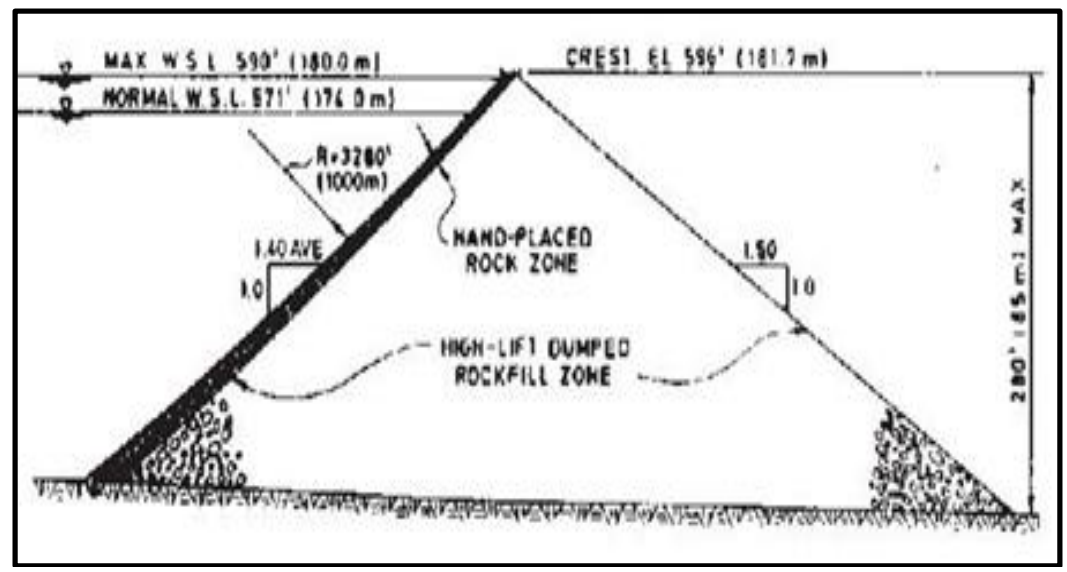

Figure 27: Typical cross section of Cogoti Dam [24]. 
Local rocks, which consists primarily of andesitic breccia, was used for construction. The main rock fill zone was started by blasting some of the abutment rocks and allowing the blasted rock fragments to fall freely on the foundation. Following completion of the required abutment excavation, rockfill was dumped in lifts as thick as could be practical, and without mechanical compaction or sluicing.

The flexible, impervious, segmented reinforced concrete face was placed on a $2 \mathrm{~m}$ thick bedding zone of hand-placed, small-size, rock. It was designed as individually formed slabs, of $10 \times 10 \mathrm{~m}$ average size, with a thickness tapering from $80 \mathrm{~cm}$ at the upstream toe to $20 \mathrm{~cm}$ at the crest of the dam. Horizontal and vertical joints with $60 \mathrm{~cm}$ wide copper water stops and rivets were provided. The spacing and bar sizes of the steel reinforcement vary as a function of elevation along the dam face, starting with a double curtain of $25 \mathrm{~mm}$ bars at $30 \mathrm{~cm}$ pacing near the toe and ending with a single curtain of $18 \mathrm{~mm}$ bars at $20 \mathrm{~cm}$ spacing at the crest.

The spillway is an ungated channel with a reinforced concrete side-channel having broad crested weir control, and was excavated in the left abutment rocks. It has a design capacity of $4,984 \mathrm{~m}^{3} / \mathrm{s}$.

On April 6, 1943, a large earthquake (M7.9) occurred approximately $200 \mathrm{~km}$ north of the City of Santiago. The earthquake centered about $95 \mathrm{~km}$ from the Cogoti Dam site; peak ground acceleration at the site was estimated to be about $0.19 \mathrm{~g}$. Substantial settlement of the dam was observed as a result of this earthquake.

The April 6, 1943, Illapel Earthquake destroyed most of the towns of Combarbala, Ovalle and Illapel, about $200 \mathrm{~km}$ north of the City of Santiago. Damage was reported in a wide area, some including the City of Santiago. However, few references, and none of these technical reports, describe this earthquake. Presumably, this is because the affected onshore area is mountainous, was sparsely populated and was probably considered of minor economic importance in 1943.

The shock was; however, felt as far away as Buenos Aires, Argentina, where dishes were broken and ink spilled from ink wells. Damage extended throughout the province of Coquimbo. A copper mine tailings dam collapsed near the City of Ovalle, killing five persons. Total reported lives lost were eleven. The epicenter was determined to be offshore, directly across the mouth of the Limari River. Earlier magnitude estimates were as high as M8.3, but were subsequently lowered to a maximum of M7.9. Many aftershocks were felt during the week that followed the earthquake.

The Illapel Earthquake was centered about $95 \mathrm{~km}$ from Cogoti Dam. An intensity IX on the Rossi-Forel scale was reported at the dam site. The reservoir is believed to be at its normal operating level at the time of occurrence of the earthquake. The principal observed effect on Cogoti Dam was to produce an instantaneous settlement of up to $41 \mathrm{~cm}$. Settlement occurred throughout the length of the crest, and the extreme upper part of the concrete face slab was exposed from the downstream side, as quoted in an internal report by Empresa Nacional de Electricidad S.A., Santiago, Chile (1972). It is of interest to note that the maximum earthquake induced settlement was about equal to that observed 4.5 years at the end of construction. The point where this settlement was measured was near the center 
of the crest, where the dam height is about $63 \mathrm{~m}$. This was not the highest dam section, which was located close to the right abutment. The settlement at the maximum dam height was less, presumably because of a restraining effect due to the nearby presence of the very steep abutment. Minor rockslides also occurred along the downstream slope of the dam.

Leakage had been observed at Cogoti Dam since the reservoir's first filling in 1939. Intermittent records have been kept over the years, which indicate leakage to be directly related to the elevation of the reservoir and probably coming through the abutment or foundation, rather than the dam itself. No significant increase in dam leakage was observed as a result of the 1943 earthquake. No face cracks were caused by the earthquake. Yearly settlement and leakage data at Cogoti Dam are presented in Figures 28 and 29.

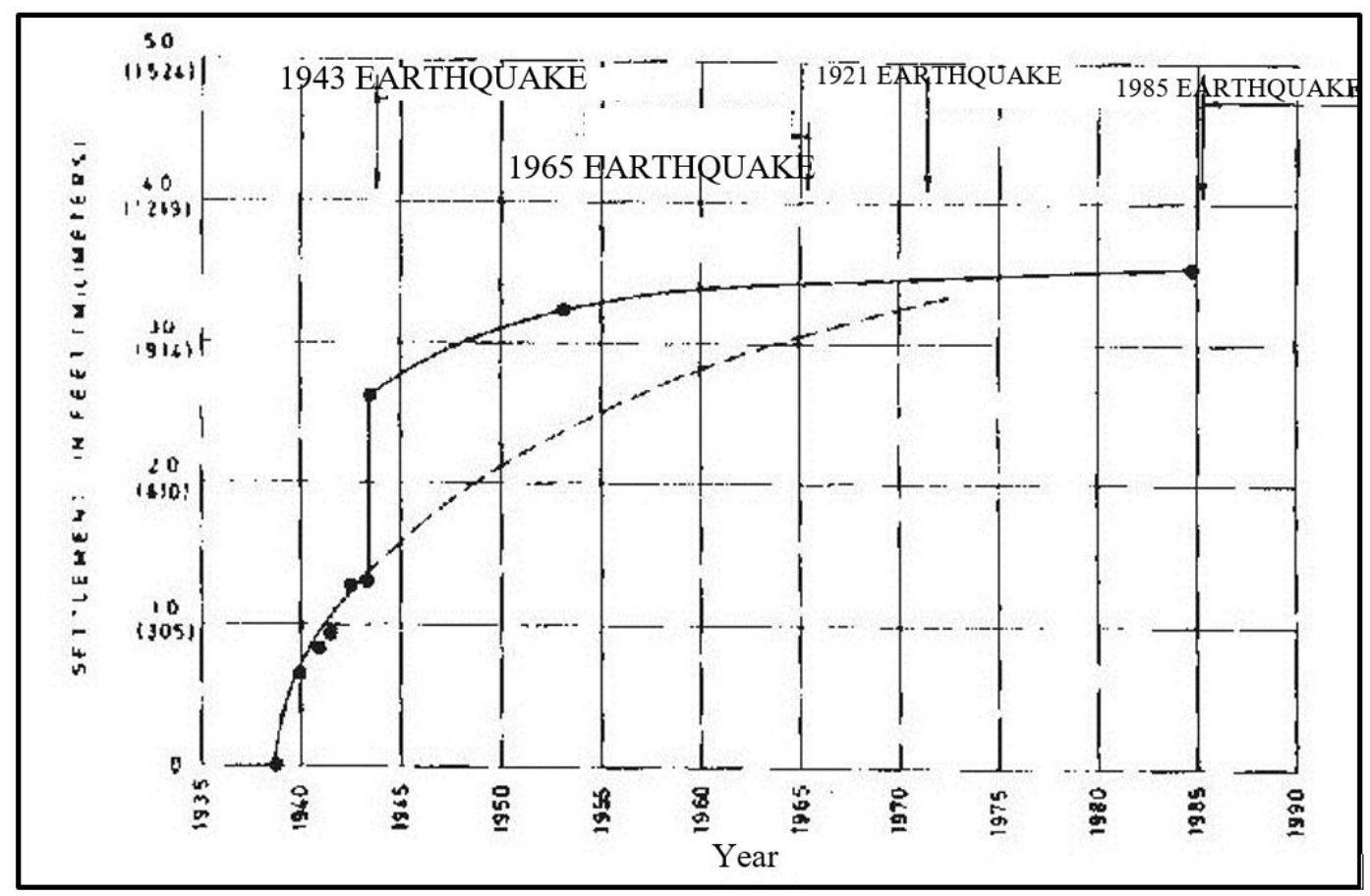

Figure 28: Crest settlement curve [24]. 


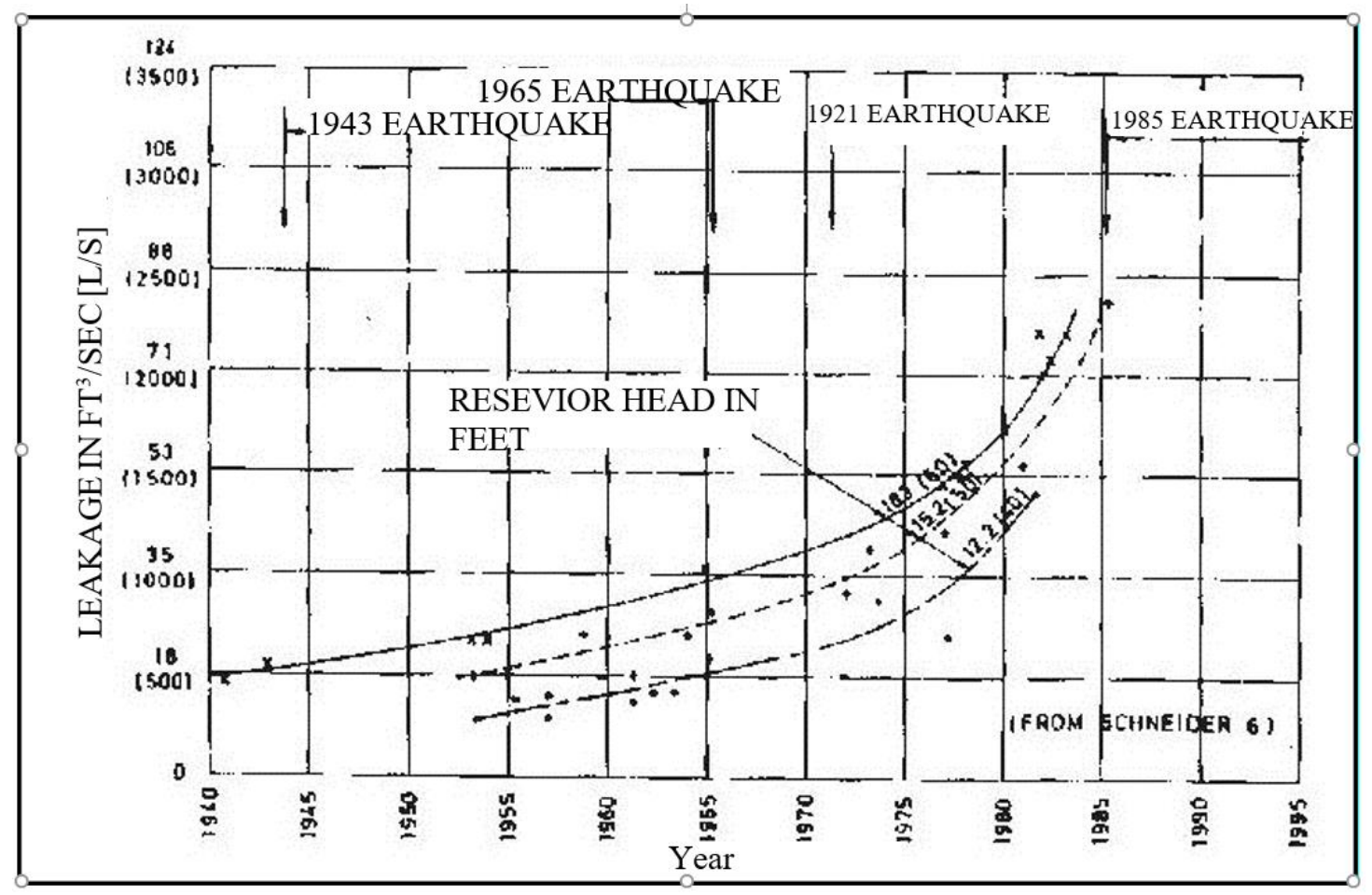

Figure 29: Leakage at Cogoti dam [24].

The dam has continued to settle after the 1943 earthquake. Interestingly, it was shaken again by three significant, although considerably more remote earthquakes: in 1965 La Ligue Earthquake, M7.1; in 1971 Papudo-Zapallar Earthquake, M7.5; and in 1985 Llolleo-Algarrobo Earthquake, M7.7. These more recent events; however, were centered at distances of more than $165 \mathrm{~km}$ from the dam and did not induce any noticeable settlement. Yet, in 1971, even though the reservoir was empty at the time of occurrence of that earthquake, the Papudo-Zapallar Earthquake caused longitudinal cracking at the dam crest and dislodged some rocks along the downstream slope.

Cogoti Dam was not instrumented at the time of the 1943 earthquake, nor were accelerometers installed that could have recorded the subsequent earthquakes. Using an attenuation equation primarily developed from Chilean earthquake data, the peak ground acceleration (PGA) induced at the Cogoti Dam site by the Illapel Earthquake was estimated to be $0.19 \mathrm{~g}$. Peak ground accelerations generated by the subsequent earthquakes were probably less than $0.05 \mathrm{~g}$; therefore, that noticeable settlements were unlikely to occur under such moderate shaking conditions.

Although significant settlement occurred due to Illapel Earthquake, the dam performed extremely well and no seismic damage was observed to the concrete face. Cogoti Dam's performance substantiates the generally accepted belief that concrete face rockfill dams have an excellent inherent capacity to withstand substantial earthquake motion without experiencing significant damage. Although Cogoti Dam's leakage has increased over the years, this has been related to aging and 
spalling of the concrete and joint squeezing, not to the 1943 Illapel Earthquake nor to any of the subsequent earthquakes to which the dam was exposed [24].

Leakage increased from $2001 / \mathrm{sec}$ to $14001 / \mathrm{sec}$ after the earthquake and, after repairing it decreased to $4001 / \mathrm{sec}$.

On 14 October 1997, the magnitude M6.8 Punitaqui Earthquake with epicentral distance of $20 \mathrm{~km}$ and focal depth of $30 \mathrm{~km}$, produced a PGA of $0.19 \mathrm{~g}$ and a crest settlement of $15 \mathrm{~cm}$. No damage was reported from the concrete face, but some cracking did occur at the downstream face of the dam, Figure 30.
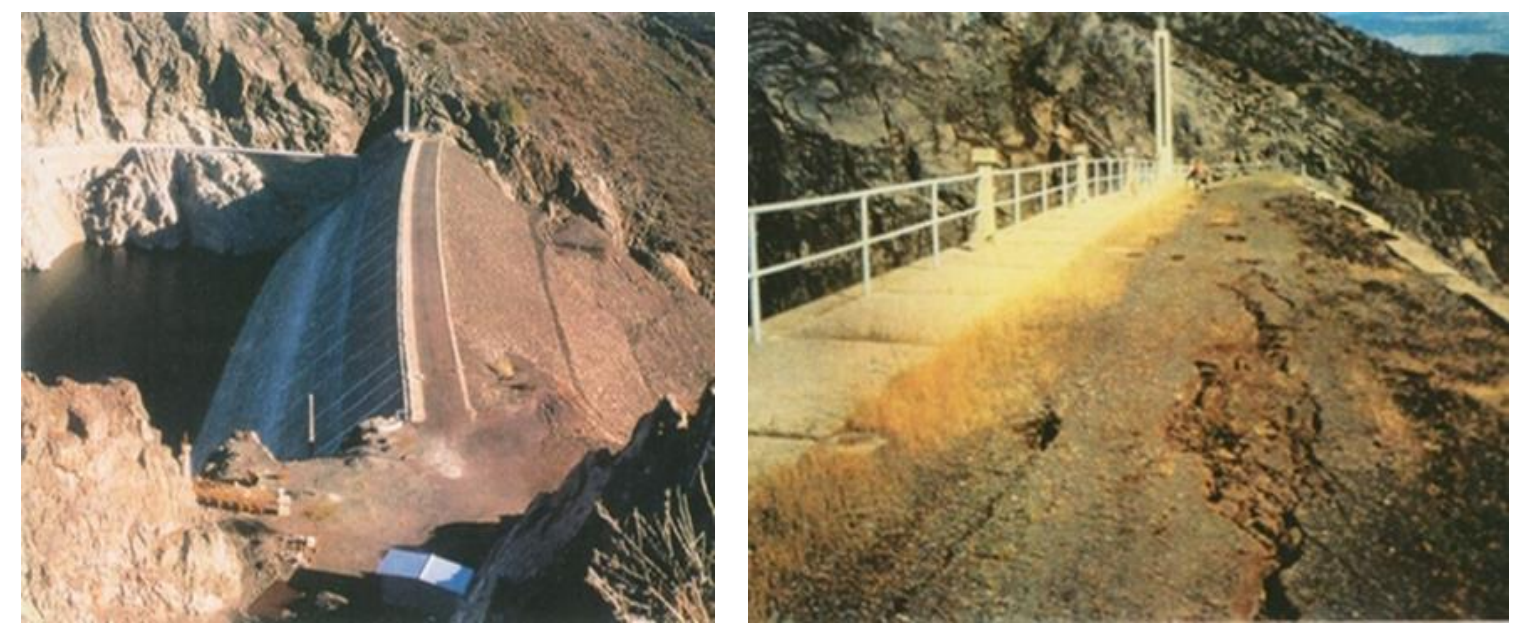

Figure 30: (Left) General view of the dam. (Right) A close up view of the dam crest showing longitudinal cracking [25].

The absence of strong motion accelerometer at this dam site is regrettable; as valuable information on the actual response of the dam could have been obtained from the recordings of PGA's acting on dam; therefore, dynamic analysis of the dam was not performed [25].

Moreover, the near-field response of the concrete slab facing still needs to be tested both in experiments and during a strong seismic event. An example is the $85 \mathrm{~m}$ high Cogoti CFR Dam in Chile [26].

\section{Concrete Dams Response to observed PGAs During Earthquakes}

From the recorded response of concrete dams to earthquake ground shacking, it can be seen that these dams generally fare better than embankment dams under seismic loads. Large number of concrete dams have been shaken by earthquakes close to dam sites, but only few have suffered major damages. In fact, during the last fifty years, many such dams experienced peak horizontal ground accelerations (PHGA) greater than $0.3 \mathrm{~g}$. The most severely shaken dams included all principal types of concrete structures: arch, multiple arch, gravity buttress and RCC dams. Generally, concrete dams had performed extremely well when subjected to earthquake 
motions, even when shaken by forces far in excess of their design loading. It has become apparent that the most significant factor in determining the response of concrete dams is the PHGA and probably the spectral acceleration at the natural frequency of the dam.

No significant damage has ever been suffered by an arch dam, although three such structures have historically experienced substantial ground motions. Concrete buttress dams when subjected to severe shaking have developed horizontal cracks at the elevation high in the dam where the downstream buttresses intersect the vertical "chimney" section. This is an area where the stiffness of the concrete structures significantly changes. Roller-compacted concrete dams; Shapai arch Dam in China and Miyatoko Dam in Japan, performed no differently to date than a dam built of conventionally placed concrete despite concern by some of less strength at the many lift joints.

The only recorded case of concrete dam failure is the case of Shih Kang gravity Dam (Taiwan) which was completed in 1977. The dam suffered of vertical left side displacement of $36 \mathrm{ft}$, a vertical right side displacement of dam $7 \mathrm{ft}$ and a diagonal offset of $23 \mathrm{ft}$. The line of fault produced by Chi-Chi Earthquake, M7.6 September 21,1999 , passed exactly under the dam and peak acceleration recorded 0.3 miles away was horizontal $0.51 \mathrm{~g}$ and vertical $0.53 \mathrm{~g}$. The dam suffered of cracking along the ogee crest, along lift lines at point of changes in geometry and the dam separated from foundation. This case, however, may be considered the most extreme case due to the fact that the distance of the dam from the line of fault was zero, and the PGAs were so high, Figure 31 [27].

The location of the dam site is shown in Figure 32 [28].

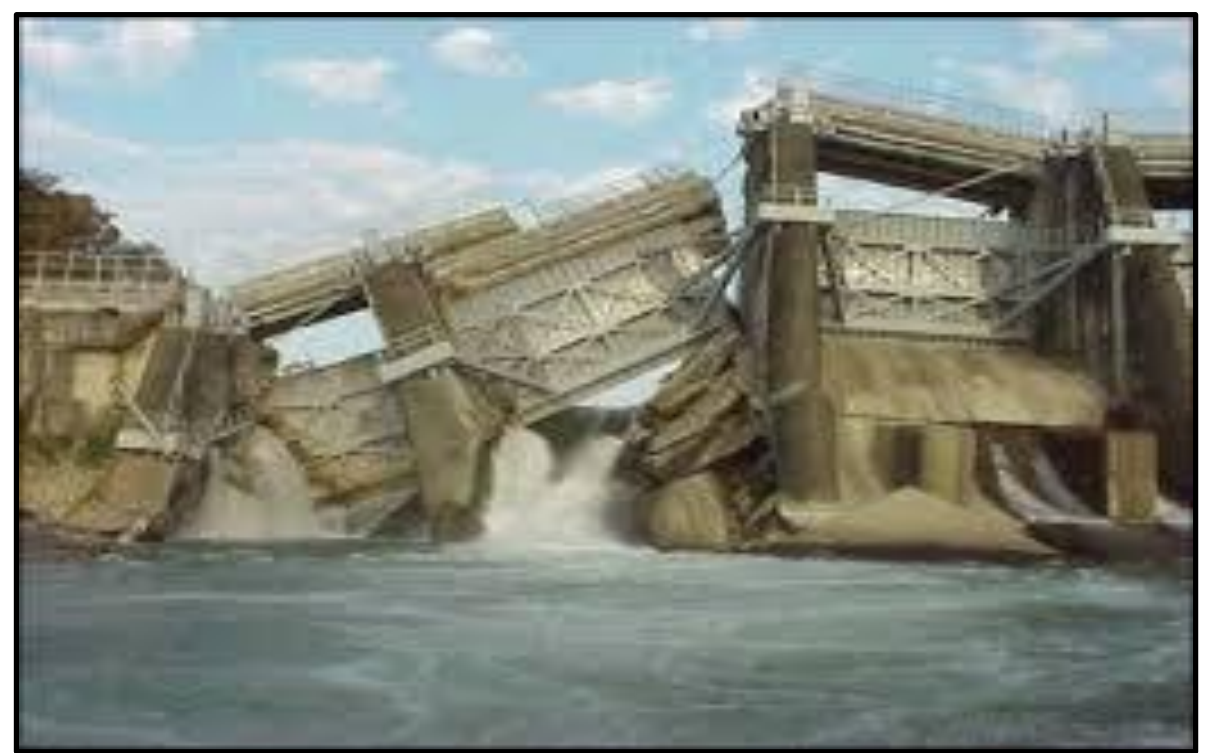

Figure 31: Shih Kang gravity dam immediately after the Chi-Chi Earthquake on September 21 ${ }^{\text {st }}$, 1999 [27]. 
The availability nowadays of high quality strong motion records derived from refined strong motion accelerometers, at or close to dam site, has enhanced our knowledge of dams' behavior in response to earthquakes. Correlation of the type and magnitude of damage with the measured PGAs at dam sites is possible now which helps in better designs of future dams.

Since the 1979, many large magnitude earthquakes have occurred as expected. With a greater number of higher quality strong motion instruments located at or near dams, our base of knowledge of the magnitude of shaking to which concrete dams have been subjected has increased. Thus, the performance of severely shaken concrete dams has increased and this knowledge can be applied in a positive and beneficial manner to the design of future dams [29].

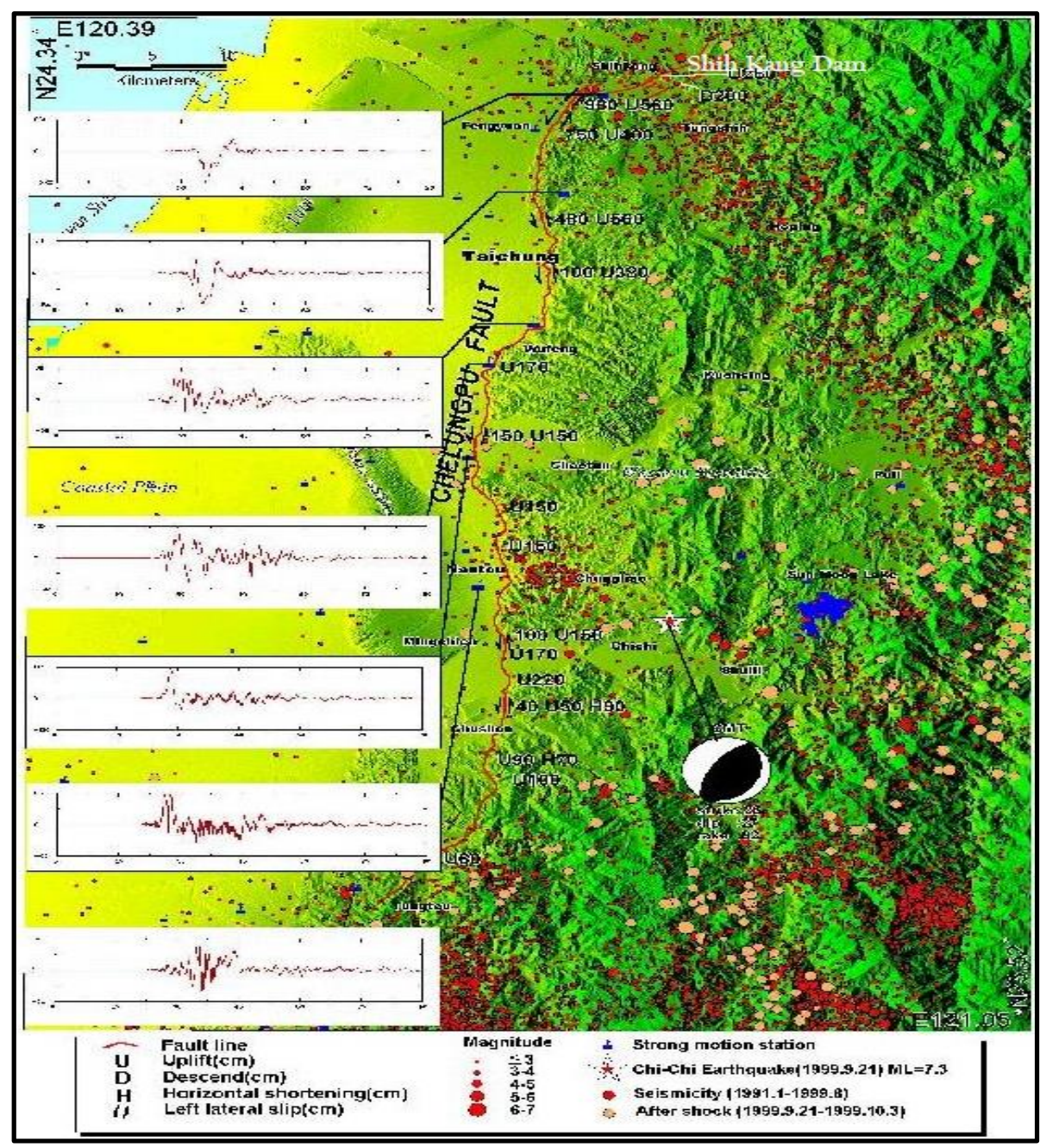

Figure 32: The Chelungpu fault, and the epicenter of the Chi- Chi earthquake. Also shown are background seismicity, strong aftershocks, E-W component velocity forms along the fault line [28]. 
In a table annexed to the same paper [29], but published in the International Water Power and Dam Construction Magazine, the response of 19 dams during earthquakes was described [30]. The table included many cases of concrete dams that were shaken by peak ground acceleration (PGA) of $0.3 \mathrm{~g}$ or more (measured or estimated). This table is reproduced in an abridged form in Table 2 which contains selected and representative cases only. More details are given on these dams in reference [27]. 
Table 2: Concrete Dams Response in Earthquakes for (PHGA > 0.3 g) (1 January, 2000) [30].

\begin{tabular}{|c|c|c|c|c|c|c|c|c|}
\hline $\begin{array}{c}\text { Dam } \\
\text { (completed) }\end{array}$ & Country & $\begin{array}{c}\text { Height } \\
\text { (m) }\end{array}$ & $\begin{array}{l}\text { Type of } \\
\text { Dam }\end{array}$ & $\begin{array}{l}\text { EQ name } \\
\text { and date }\end{array}$ & $\mathbf{M}$ & \multicolumn{2}{|c|}{$\begin{array}{c}\text { PHGA (g) } \\
{[31]}\end{array}$} & \multirow{2}{*}{$\begin{array}{c}\text { Remarks } \\
\begin{array}{c}\text { Cracks in both } \\
\text { faces }\end{array}\end{array}$} \\
\hline $\begin{array}{l}\text { Koyna } \\
(1963)\end{array}$ & India & (103) & Gravity & $\begin{array}{c}\text { Koyna } \\
\text { 11 Dec } 1967\end{array}$ & $1.8(3)$ & 6.5 & 0.63 & \\
\hline $\begin{array}{l}\text { Mingtan } \\
(1990)\end{array}$ & Taiwan & (82) & Gravity & $\begin{array}{c}\text { Chi- Chi } \\
21 \text { Sep } 1999\end{array}$ & $7.5(12)$ & 7.6 & $\begin{array}{l}0.4 \text { to } 0.5 \\
\quad(\mathrm{est})\end{array}$ & No damage \\
\hline $\begin{array}{l}\text { Kasho } \\
(1989\end{array}$ & Japan & $(46.4)$ & Gravity & $\begin{array}{l}\text { Western } \\
\text { Tottori } \\
6 \text { Oct } 2000\end{array}$ & $\begin{array}{l}1.9 \text { or } 5 \\
(3 \text { or } 8)\end{array}$ & 7.3 & $\begin{array}{c}0.54 \text { b } 2.09 \\
\mathrm{c}\end{array}$ & $\begin{array}{l}\text { Cracks in Control } \\
\text { Building at crest }\end{array}$ \\
\hline $\begin{array}{c}\text { Miyatoko } \\
\text { RCC (1993) }\end{array}$ & Japan & (48) & $\mathrm{RCC}$ & $\begin{array}{c}\text { Tohoku } \\
11 \text { Mar } 2011\end{array}$ & 84 (135) & 9.0 & $>0.7$ & No Damage \\
\hline $\begin{array}{l}\text { Takou } \\
(2007)\end{array}$ & Japan & (77) & Gravity & $\begin{array}{c}\text { Tohoku } \\
11 \text { Mar } 2011 \\
{[4]}\end{array}$ & 68 (109) & 9.0 & $>0.4$ & $\begin{array}{c}\text { Cracking of } \\
\text { gatehouse walls at } \\
\text { crest }\end{array}$ \\
\hline $\begin{array}{c}\text { Bear Valley } \\
(1912,1988)\end{array}$ & USA & (28) & $\begin{array}{l}\text { Multiple } \\
\text { arch } \\
\text { modified } \\
\text { to gravity } \\
\text { dam in } \\
1988\end{array}$ & $\begin{array}{c}\text { Landers } \\
\text { 28 Jun 1992, } \\
\text { Big Bear 29 } \\
\text { Jun } 1992\end{array}$ & $\begin{array}{l}28(45) \\
9(14.5)\end{array}$ & $\begin{array}{l}7.4, \\
6.6\end{array}$ & 0.57 & $\begin{array}{c}\text { Multiple arch } \\
\text { modified to gravity } \\
\text { dam in 1988. No } \\
\text { damage, except } \\
\text { slight displacement } \\
\text { of crest bridge } \\
\text { girders }\end{array}$ \\
\hline $\begin{array}{c}\text { Gibraltar } \\
(1920,1990)\end{array}$ & USA & $(52)$ & $\mathrm{RCC}$ & $\begin{array}{l}\text { Santa Barbara } \\
\text { 29 Jun } 1925\end{array}$ & $\begin{array}{l}6.5 \text { and } \\
6.8\end{array}$ & 6.3 & $>0.3$ (est) & $\begin{array}{l}\text { No damage. } \\
\text { Modified in } 1990 \\
\text { with RCC }\end{array}$ \\
\hline $\begin{array}{l}\text { Rapel } \\
(1968)\end{array}$ & Chile & (110) & Arch & $\begin{array}{l}\text { Santiago } 3 \\
\text { Mar } 1985\end{array}$ & $28(45)$ & 7.8 & $\begin{array}{l}0.31 \text { near } \\
\text { dam }\end{array}$ & $\begin{array}{c}\text { Damage to } \\
\text { spillway and intake } \\
\text { tower, dam } \\
\text { performed well }\end{array}$ \\
\hline $\begin{array}{l}\text { Techi } \\
(1974)\end{array}$ & Taiwan & (185) & Arch & $\begin{array}{l}\text { Chi-Chi } 21 \\
\text { Sept. } 1999\end{array}$ & & 7.6 & $\begin{array}{c}0.5 \mathrm{~b} 0.86 \\
\mathrm{c}\end{array}$ & $\begin{array}{l}\text { Local cracking of } \\
\text { curb at dam crest }\end{array}$ \\
\hline $\begin{array}{l}\text { Shapai RCC } \\
\text { (2003) }\end{array}$ & China & (132) & $\mathrm{RCC}$ & $\begin{array}{l}\text { Wechuan } 12 \\
\text { May } 2008\end{array}$ & $7.8(12)$ & 8.0 & $>0.5$ (est) & No damage \\
\hline $\begin{array}{l}\text { Sefid Rud } \\
\text { (1962) }\end{array}$ & Iran & $(106)$ & Buttress & $\begin{array}{c}\text { Manjil 21 Jun } \\
1990\end{array}$ & $\begin{array}{c}\text { Near } \\
\text { dam site }\end{array}$ & 7.7 & 0.714 (est) & $\begin{array}{l}\text { Horiz, cracks near } \\
\text { crest, minor disp, } \\
\text { of blocks }\end{array}$ \\
\hline $\begin{array}{l}\text { Legend: } \\
\text { M=Magni }\end{array}$ & aI & Lat & $\begin{array}{r}\text { an } 6.5 \text { an } \\
\text { horiz }\end{array}$ & $\begin{array}{l}\text { S above } 6.5 \\
1 \text { ground ac }\end{array}$ & $\begin{array}{l}\text { ), Surf } \\
\text { ration }\end{array}$ & & $\begin{array}{l}\mathrm{t}, \mathrm{Ht}=\mathrm{I} \\
=\mathrm{After}\end{array}$ & $\begin{array}{l}\text { ht, V=Vertical, } \\
\text { k, PHGA=Peak }\end{array}$ \\
\hline
\end{tabular}


The analysis of the seismic response of a concrete dam is a complex problem in which the accurate representation of the material's behavior requires some form of nonlinear model, especially if the concrete material is subjected to significant tensile stress demands. In case of severe ground motions, considerable cracking is likely to develop across extensive regions of the dam, particularly at the dam heel and in the vicinity of abrupt changes in geometry. Therefore, the proper consideration of this nonlinear phenomenon and its consequences on the dynamic response of the system become critically important for a rigorous seismic evaluation. The actual postcracking behavior and the ultimate capacity of existing concrete dams can only be determined by performing the corresponding nonlinear dynamic analyses [32]. This analysis requires the seismic spectra measured on dam sites or nearby sites as an input data in addition to material properties assumed for linear and nonlinear dynamic analyses.

\section{Summary Points and Conclusions}

7.1 Since the late 1980s, the need for rational method of design for moderate or significate risk dams has raised the need for using seismic monitoring instrumentation in dam sites. These were required for recording peak ground acceleration and its variation with time during the event, together with the three dimensional displacements in dam body and deformations of its slopes. Recording the response of pore pressure devices accompanying the measured PGAs was also done. The development of equipment for transmitting these information and observation to observation centers helped relaying them from remote sites. Nearly, all seismic instruments in use today utilize servoaccelerometers that have the ability to measure motion in a single horizontal, vertical, or transverse planes. Most of the devices are considered "strong motion" instruments that record significant movements.

7.2 Seismic instrumentation of dams and reservoirs' sites is accepted nowadays not as luxury items for research work, but mainly to understand significant seismic hazards facing existing dams in seismic areas and even desirable in traditionally non-seismic areas. With the advent of digital seismic equipment, it can now be an integral part of dam safety monitoring works. The digital earthquake data can be gathered by site personnel and remote control centers by use of computers. When digital instruments are installed with modem and communication means, then remote access from several offices is made available. Seismic instruments' recordings taken from existing dam sites help also in the safe design of new dams in seismically similar regions.

7.3 The increased awareness of the importance of seismic instrumentation in dams have led to installing them in large number in strategic dams. Examples are given of two cases only for demonstration, but many more are given in manufacturers literature. Many high caliber manufactures are available in the world nowadays; their literature shows the degree of advancement in 
instruments manufacturing, software development and progress in data transfer equipment. Seismic instrumentations are costly to install, run and maintain, but all agree on their extreme value which justifies their use in dams and make their installation highly recommendable.

7.4 Normally, recorded parameters are the maximum ground acceleration (PGA) caused by an earthquake of magnitude (M) whose focus is at known distance from the dam. Damage sustained by dams after an earthquake can be matched with the recordings of the seismic instruments used at dam sites. Apart from PGAs, other obtained recordings are the time history and frequency of the event so a full picture is formed. The correlation of damage with the seismic records gives good guide in selecting the most suitable type of a future dam in any seismic region. Seismic measurements show that concrete dams are less affected by earthquakes than embankment dams under similar seismic loading conditions, and even that rockfill dams have better performance than earthfill dams. We have tried to explain this by presenting many case histories of dams in terms of increased seepage, settlement, displacement and cracking. From these and many other documented cases, there are lessons to be learnt by designers of the best ways to handle any new design or the best rehabilitating and upgrading program needed for damaged existing dams.

7.5 It was possible from seismic measurements and dynamic analyses of affected dams to discover the reasons why concrete dams have performed well and invariably better than that predicted by design or analysis when shaken by an earthquake. These reasons may be:

i) the redundancy of the damaged structure to redistribute load.

ii) the duration of strong shaking being too short to cause sizable damage.

iii) the increase in the tensile strength of the concrete during dynamic loading that increases resiliency.

iv) increase in the damping that reduces the seismic impact on the dam.

v) reduced seismic impact because the natural frequency of the dam does not match the frequency of the earthquake, and

vi) the three-dimensional effects of canyon confinement or dam geometry (curvature) that help prevent failure [30].

7.6 It may be seen from the foregoing that, seismic instrumentation for measuring and recording peak ground acceleration (PGA) and related parameters at dams' sites during earthquake adds to dam safety precautions. They are as valuable to dam safety as other conventional dam instrumentation, their use is therefore highly desirable and recommendable. 


\section{References}

[1] USCOLD (2000). Observed Performance of Dams during Earthquakes. Vol. II, October 2000, pp.15- 20.

http://www.ussdams.org/wpcontent/uploads/2016/05/ObservedPerformanceII _V2.pdf

[2] USBR (1987). Concrete Dams Instrumentation Manual. Page12. https://www.usbr.gov/tsc/techreferences/mands/mands-pdfs/CDamInst.pdf

[3] Mihailov, V. and Dojcinovsky, D. (2004). Strong Motion Instrumentation of Dams in Macedonia-Some Experience and Results. 13th World Conference on Earthquake Engineering Vancouver, B.C., Canada, August 1-6, 2004, Paper No. 475. https://www.iitk.ac.in/nicee/wcee/article/13_475.pdf

[4] National Research Council (1990). Earthquake Engineering for Concrete Dams: Design, Performance, and Research Needs. Panel on Earthquake Engineering for Concrete Dams, Committee on Earthquake Engineering. National Academy Press Report pp.33-35. Washington, D.C. 1990.

https://www.nap.edu/catalog/1742/earthquake-engineering-for-concretedams-design-performance-and-research-needs

[5] FEREC (n.d.). Instrumentation and Monitoring. Chapter 9, pp.20, 31. https://www.ferc.gov/industries/hydropower/safety/guidelines/engguide/chap9.pdf

[6] Wikipedia (2012). Seismometer. Retrieved on 10th June 2020. https://en.m.wikipedia.org/wiki/Seismometer

[7] Engineering 360 (n.d.). Seismic Instruments Information. Retrieved on $10^{\text {th }}$ June 2020. https://www.globalspec.com/learnmore/sensors_transducers_detectors/accele ration_vibration_sensing/seismic_instruments

[8] Dewey, J. and Byerlym, P. (2004). The Early History of Seismometry to 1900. USGS. Last modification on 23 January 2004. Retrieved on 10th June 2020. https://web.archive.org/web/20060622213909/http://neic.usgs.gov/neis/seism ology/part02.html

[9] Bartholomew, C. L. and Haverland, M. L. (1987). USBR Concrete Dams Instrumentation Manual.. USBR, October 1987, pp.121- 125.

https://www.usbr.gov/tsc/techreferences/mands/mands-pdfs/CDamInst.pdf

[10] Evangelidis, C. (2018). Seismic monitoring of Large Dams. Alliance for Disaster Risk Reduction (ALTER). Retrieved on 10th June 2020.

http://alter-project.eu/wpcontent/uploads/2018/12/ALTER_seismic_monitoring.pdf

[11] GeoSig (n.d.). Seismic Instrumentation and Monitoring of Dams. Switzerland. Retrieved on 10th June 2020. https://www.geosig.com/Dams-pg38.aspx 
[12] USACE (1995). Instrumentation of embankment Dams and Levees. Manual No. 1110-2-1908, 30 June 1995. Chapter 4, pp.19-21. Washington, DC. https://www.publications.usace.army.mil/Portals/76/Publications/EngineerM anuals/EM_1110-2-1908.pdf

[13] Nile Alley (2017). Aswan High Dam. Retrieved on 12th June 2020. http://www.nilecruised.com/aswan-high-dam/

[14] Water Technologies (n.d.). Aswan High Dam, River Nile, Sudan, Egypt. Retrieved on 12th June 2020.

https://www.water-technology.net/projects/aswan-high-dam-nile-sudanegypt/

[15] McKenna, E. (n.d.). Aswan High Dam. Encyclopedia Britannica. Retrieved on 12th June 2020. https://www.britannica.com/topic/Aswan-High-Dam

[16] REFTEK (2013). Strong Motion Structural Monitoring Technology is used on the Aswan Dams. May 2013. Retrieved on 12th June 2020. https://reftek.com/ref-teks-strong-motion-structural-monitoring-technologyused-aswan-dams/

[17] GeoSig (n.d.). Dams- Enguri dam- Georgia. Retrieved on 13t June 2020. https://www.geosig.com/Dams---Enguri-Dam--Georgia-pg101.aspx

[18] de Gali Price, C. H. and Christianson, K. J. (2019). The Legacy of Edgecumbe the 1987 Earthquake. Proceeding of the 7th International Conference on Earthquake Geotechnical Engineering for Protection and Construction. Edited by Silvesti F, Moraci N. Rome, Italy 17- 20 June 2019, pp.1994-2001. https://books.google.se/books?id=_Jq4DwAAQBAJ\&pg=PA2000\&lpg=PA2 $000 \& \mathrm{dq}=$ matahina + dam+history $\&$ source $=\mathrm{bl} \& \mathrm{ots}=\mathrm{uGoSK} 1 \mathrm{vbX} 9 \& \mathrm{sig}=\mathrm{ACfU}$ 3U376Sx83-

2Caf5j2zpL_cYLOV_pTA\&hl=sv\&sa=X\&ved=2ahUKEwjew52zk_LpAhW IE5oKHYfwBhEQ6AEwEHoECAgQAg\#v=onepage \&q=matahina\%20dam $\% 20$ history\&f=false

[19] USCOLD (1992). Matahina Dam, New Zealand. Observed Performance of Dams During Earthquakes. Vol.1, pp.101-109.

http://www.ussdams.org/wpcontent/uploads/2016/05/ObservedPerformanceIs _v1.pdf

[20] McKinnon, M. (2015). Floodway, Lake Matahina. TERA, the Encyclopedia of New Zealand. Updated 1 Jul 2015. Retrieved on 15th June 2020. https://teara.govt.nz/en/photograph/5711/floodway-lake-matahina

[21] Gillon, M. D. (1988). The Observed Seismic Behavior of Matahina Dam. International Conference on Case Histories in Geotechnical Engineering. Session 4/25. https://scholarsmine.mst.edu/cgi/viewcontent.cgi?article=1556\&context=icch ge 
[22] USSD (2000). Observed Performance of Dams During Earthquakes. Vol. II, pp.80-89, October 2000.

http://www.ussdams.org/wpcontent/uploads/2016/05/ObservedPerformanceII -V2.pdf

[23] Pelecanos, L., Kontoe, S. and Zdravković, L. (2017). The Effects of DamReservoir Interaction on the Nonlinear Seismic Response of Earth Dams. Journal of Earthquake Engineering, pp.1034-1056, 15 May 2017. Published online:19 April 2018.

https://www.tandfonline.com/doi/full/10.1080/13632469.2018.1453409

[24] USCOLD (2000). Observed Performance of Dams During Earthquakes. Vol.II, pp.72- 75, October 2000.

http://www.ussdams.org/wpcontent/uploads/2016/05/ObservedPerformanceII -V2.pdf

[25] Wieland, M. (2009). CFRD's in highly seismic regions. Published on 14th April 2010 by Water Power and Dam Construction Magazine. Originally presented at the First International Symposium on Rockfill Dams, held in Chengdu, China from 18-21 2009. https://www.waterpowermagazine.com/features/featurecfrds-in-highlyseismic-regions/

[26] Wieland, M. (2003). Seismic Aspects of Dams. Q83 General report. Proceedings of the 21st Congress of the International Commission on Large Dams, pp.1233- 1362. Montreal, June 2003. https://www.academia.edu/18384707/0_Wieland_ICOLD_Montreal_General _ReportQ83_seismic_aspects_of_dams

[27] USSD (2017). Seismic Analysis of Concrete Dams Workshop Annual Conference. April 6-7, 2017.

http://www.ussdams.org/wp-content/uploads/2016/05/Session1_CaseHistories-and-Seismic-PFM.pdf

[28] Tsai, Y. B. and Huang, M.W. (2000).Strong Motion Characteristics of the ChiChi Taiwan 1999 earthquake. http://www.ctsee.org.tw/pdf/ee0201/es0201-1.pdf

[29] Hansen, K. D. and Nuss, L. K. (2001). Lessons learned from the earthquake performance of concrete dams. Proceedings of 15th European Conference on Soil Mechanics and Geotechnical Engineering, p.7. 12-15 September 2011. http://www.hssmge.gr/TEFXOS_No_39_SEPTEMBER_2011.pdf

[30] Hansen, K. D., Nuss, L. K. and Roehm, L. (2011). Lessons learned from the earthquake performance of concrete dams. International waterpower and Dam Construction Magazine, Table (1), 27 September 2011. https://www.waterpowermagazine.com/features/featurelessons-learned-fromthe-earthquake-performance-of-concrete-dams/ 
[31] Kanamori, H. (1983). Magnitude Scales and quantification of Earthquakes. Tectonophysics Journal 93 (1983), pp.185-199. Elsevier 1983.

http://gps-prod

storage.cloud.caltech.edu.s3.amazonaws.com/people_personal_assets/kanam ori/HKtect83b.pdf

[32] Yamaguchi, Y., Hall, R., Sasaki, T., Matheu, E., Kanenawak, K., Chudgar, A. and Yule, D. (2004). Seismic Performance Evaluation of Concrete Gravity Dams. Proceeding of the 13th World Conference on Earthquake Engineering Vancouver, B.C., Canada. August 1-6, 2004 Paper No. 1068, p.5.

https://www.researchgate.net/publication/268428812_Seismic_Performance_ Evaluation_of_Concrete_Gravity_Dams 